\title{
Preliminary report on ichthyopterygian elements from the Early Triassic (Spathian) of Spitsbergen
}

\author{
Christina Pokriefke Ekeheien', Lene Liebe Delsett' ${ }^{1}$ Aubrey Jane Roberts ${ }^{2}$ \\ \& Jørn Harald Hurum ${ }^{1}$
}

${ }^{1}$ Natural History Museum, University of Oslo, Pb.1172 Blindern, N-0318 Oslo, Norway.

${ }^{2}$ Natural History Museum, London, United Kingdom.

E-mail corresponding author (Lene Liebe Delsett): l.l.delsett@nhm.uio.no

Jaw elements of Omphalosaurus sp. are described from the Early Triassic (Spathian) of Marmierfjellet, Spitsbergen. The elements are from the Grippia and the Lower Saurian niveaus in the Vendomdalen Member of the Vikinghøgda Formation. In the Grippia niveau a bonebed was excavated in 2014-15 and a large number of ichthyopterygian elements were recovered. Together with the omphalosaurian jaw elements a collection of large vertebral centra were recognized as different from the smaller Grippia centra and more than 200 large vertebral centra are referred to Ichthyopterygia indet. and tentatively assigned to regions of the vertebral column. We refrain from further assignment due to the systematic position and the difficulty of defining criteria for recognizing postcranial elements of Omphalosaurus.

Keywords: Ichthyopterygia, Spitsbergen, Triassic, Omphalosaurus, Grippia bonebed

Electronic Supplement A: Supplementary Material

Received 23. November 2017 / Accepted 21. August 2018 / Published online 4. October 2018

\section{Introduction}

The Early Triassic deposits of Svalbard contain large amounts of fish, amphibian and reptilian fossils from the early radiations after the $\mathrm{P} / \mathrm{T}$ mass extinction and have been known for more than one hundred years (Wiman, 1910; Maxwell \& Kear, 2013; Hurum et al., 2018). The informal Grippia niveau was established for the layer where the ichthyopterygian Grippia longirostris was found (Wiman, 1928, 1933). In 2014-15, the Spitsbergen Mesozoic Research Group collected ichthyopterygian material from a bonebed in the Grippia niveau and in the Lower Saurian niveau (Hurum et al., 2018), and in this material were some massive tooth-bearing elements with two distinct morphologies and several hundred vertebral centra. Some of the skull material and a group of vertebrae with a distinct morphology are examined in this contribution.
The skull material is referred to Omphalosaurus based on the distinct tooth enamel, dome-shaped teeth and an overall similar morphology to other specimens of the genus (Sander \& Faber, 2003). This is the stratigraphically oldest material of Omphalosaurus described from Spitsbergen, while remains of Spathian age are previously known from Nevada (Mazin \& Bucher, 1987). Omphalosaurus is a poorly known animal that inhabited the shallow seas in the Eastern Pacific, the Boreal Sea and Western Tethys in the late Early to Middle Triassic. The genus was erected based on a fragmentary skull and two associated vertebrae from the Middle Triassic of Nevada (Merriam, 1906) and material has later been described from Spitsbergen, Germany and Poland (Wintrich et al., 2017). There is a lack of complete and articulated skeletons, and there are many unanswered questions about the morphology and systematic affinity of the taxon. While some claim it to 
be ichthyopterygian (Kuhn, 1934; Huene, 1956; Cox \& Smith, 1973; Mazin, 1983; 1986; Tichy, 1995; Sander \& Faber, 1998, 2003; Sander, 1999; Wintrich et al., 2017) others doubt ichthyopterygian affinities (Maisch \& Matzke, 2000; Motani, 2000; Maisch, 2010).

The vertebrae are described together due to their shared morphology, but it is unknown whether they actually belong to the same taxon. They are referred to Ichthyopterygia based on a relatively short anteroposterior length compared to dorsoventral height (Sander, 2000) and differ clearly from two other vertebral morphologies in the bonebed; that of a smaller taxon, possibly Grippia, and that of Cymbospondylus, which are both under study (Engelschiøn et al., 2018). Ichthyopterygian vertebrae are interesting because the shape is influenced by locomotion patterns, and the microanatomy by growth rates and patterns (Buchholtz, 2001; Houssaye et al., 2018).

\section{Geological setting}

The material described herein was collected in 2014 and 2015 at the western side of Marmierfjellet, in the hills of Flowerdalen (Fig. 1), from the Grippia and the Lower Saurian niveaus. The deposits are part of the Sassendalen Group, Vikinghøgda Formation, Vendomdalen Member, dated as Spathian (Mørk et al., 1999; Hansen et al., 2018). The Grippia niveau is somewhat older than the Lower Saurian niveau at 247.2 Ma (Hansen et al., 2018). The Grippia bonebed (Fig. 2) is a thin layer with a pebbly appearance which preserves disarticulated skeletal elements and teeth from fish and reptiles, shark teeth and coprolites (Bratvold et al., 2018). The fossils in the bonebed show a size range of a few $\mathrm{mm}$ up to $20 \mathrm{~cm}$. The bonebed is deposited in an open water environment (Mørk et al., 1999). The varying weathering and size of the elements suggest that the bonebed is composed of distal transported material, brought from shallow to open water by storm events which probably caused the mix of shallow water species with more open water species such as Omphalosaurus. Except for a single bivalve, no invertebrates or burrow tracks were preserved in this part of the bonebed, suggesting that bottom conditions were unfavourable. The lack of pelagic invertebrates with aragonitic shells could be due to dissolution. Bottom currents might have winnowed the material continuously, so that thin shelled fragments were crushed, while skeletal elements were eroded slowlier.

\section{Material and methods}

The skeletal elements were collected as surface material and as bulk together with surrounding matrix. The GPScoordinates of the excavation site are UTM: N78.30521
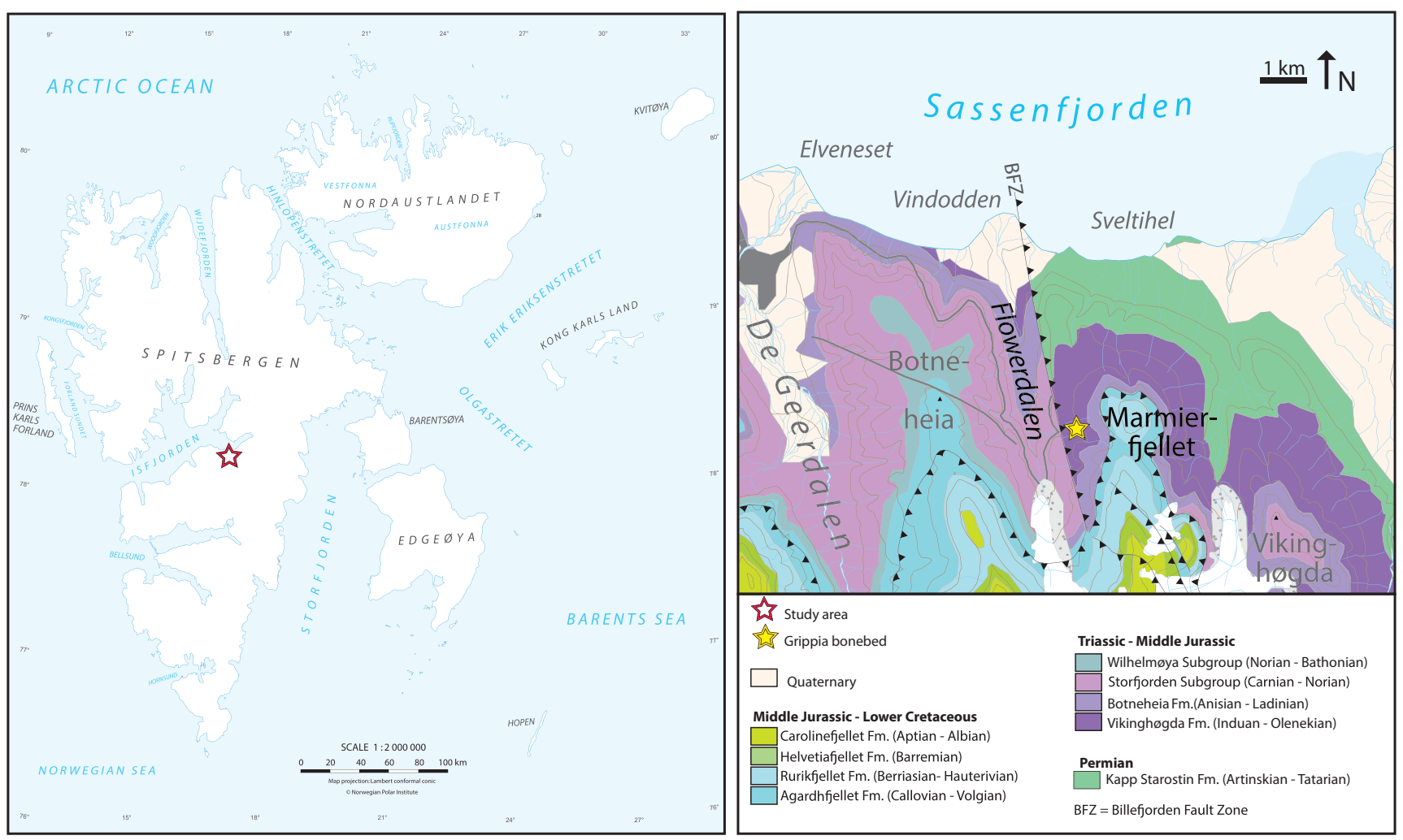

Figure 1. The map shows an overview of Svalbard and geological map of the study area in central Spitsbergen. The star marks the site of the Grippia bonebed. Modified from Dallmann (2015). 


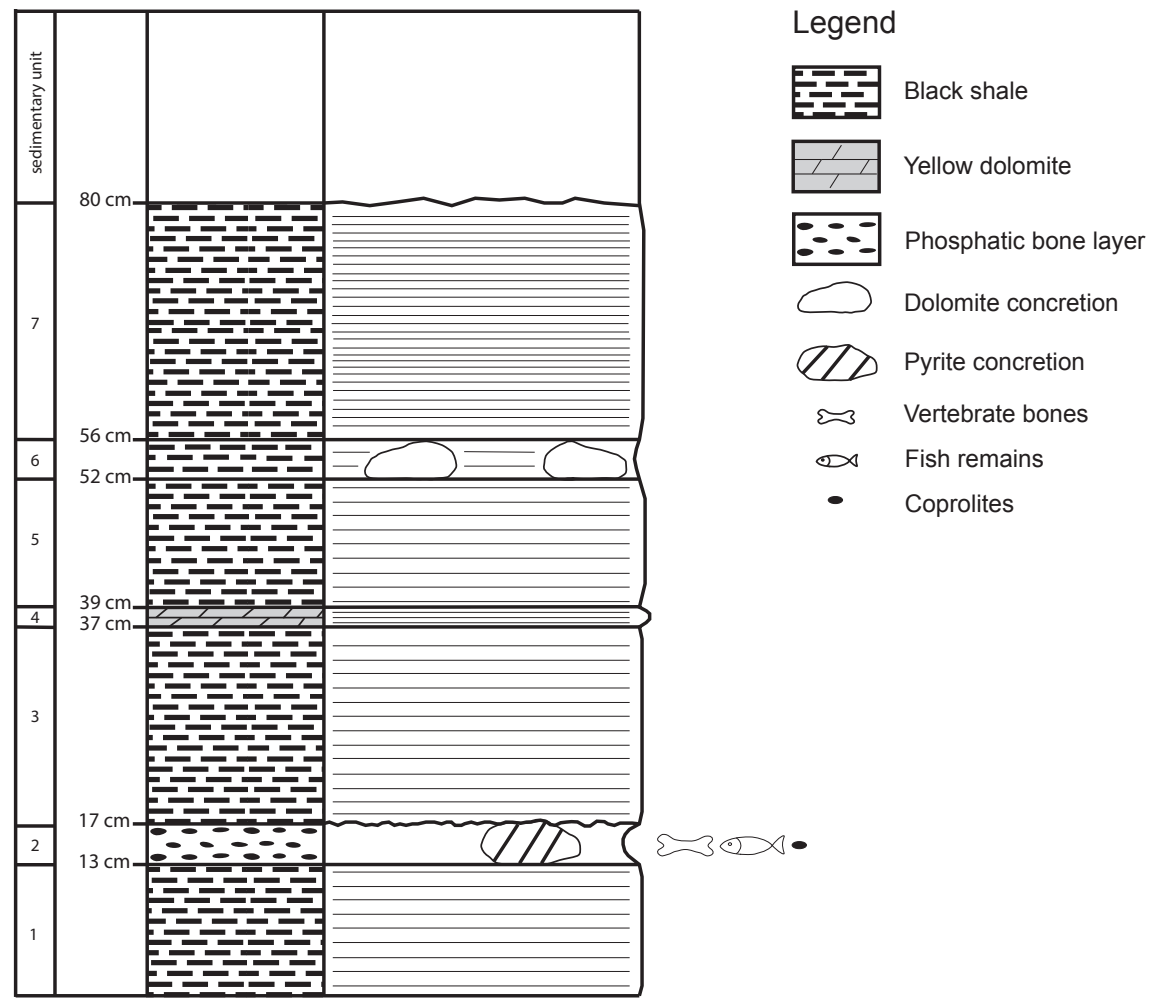

Figure 2. Detailed sedimentological log of the Grippia bonebed. Grippia bonebed is represented by sedimentary unit 2.

E016.60118. The bonebed was collected in quadrants of 1 x 1 meter. For simplicity, the "Grippia bonebed" will be used for the material excavated from the bonebed (Fig. 2) while the niveaus will be used as reference for the collected surface material. The material is kept at the Natural History Museum, University of Oslo (list in Electronic Supplement A). The material differ in the degree of wear because it consists to a large degree of surface material. As there are a higher number of vertebrae, the less eroded are pictured, while the jaw fragments are fewer, and some show a large degree or erosion. Because of this, caution should be taken in the interpretation. In 2016 more material was excavated that is currently under preparation, of which some seem to have nice three-dimensional preservation and might reveal additional morphological details.

18 ?dentaries and 7 ?premaxillae from Omphalosaurus could be identified. More than 30 additional fragments of tooth-bearing bones were referred to the genus, but could not be identified further. Identification of the tooth-bearing bones are based on the Omphalosaurus cf., O. nevadanus specimen MBG 1500 (pers. obs. CPE) which is the only specimen described with complete premaxillae and dentaries in articulation (Sander $\&$ Faber, 2003). Two hundred and forty vertebral centra were referred to Ichthyopterygia and were tentatively assigned to the regions of the vertebral column based on Cymbospondylus and criteria used for a broad range of ichthyopterygians (Merriam, 1908; Sander, 1992; Buchholtz, 2001). Hundred and one additional centra share morphological features, but are not assigned to regions due to poor preservation. Ichthyopterygian vertebrae of at least two other, largely different morphologies are present in the member; Cymbospondylus sp. (Engelschiøn et al., 2018) and what is possibly Grippia. The latter are longer than tall and smaller than those described here (Wiman, 1933) and three centra are included for comparison. Measurements were taken according to Sander \& Faber (2003).

\section{Abbreviations used in tables and figures}

ap - anterior process; aP - apophysis; aT - anterior tooth; $\mathrm{D}$ - dentine; dl - dental laminae; $\mathrm{dP}$ - diapophysis; $\mathrm{E}$ - enamel; em - embayment; $\mathrm{fNa}$ - facet for the neural arch; fNc - floor of neural canal; fo - foramina; fT functional teeth; gr - groove; $\mathrm{H}$ - height; L - length; ms - mandibular symphysis; $\mathrm{nF}$ - notochordal foramen; os - occlusal surface; Pc - pulp cavity; pP - parapophysis; ps - premaxillary symphysis; rT - replacement teeth; tp - triangular process; vc - vascular canals; vK - ventral keel; W - width; Y - Y-mark.

\section{Institutional abbreviations}

PMO - Natural History Museum (Palaeontological collections), University of Oslo, Oslo, Norway; PMU - 
Paleontologiska Museet, Uppsala University, Uppsala, Sweden; MBG - Museum Burg Golling, Austria; UCMP - Museum of Paleontology, University of California at Berkeley, USA.

\section{Results}

\section{Systematic palaeontology}

?lchthyopterygia Owen, 1840

Omphalosauridae Merriam, 1906

Omphalosaurus Merriam, 1906

\section{Omphalosaurus sp.}

Locality: West side of Marmierfjellet, northeast of Longyearbyen, Spitsbergen, Svalbard, Norway. Grippia bonebed.

Horizon and stage: Vendomdalen Member, Vikinghøgda Formation, Spathian, late Early Triassic.

\section{?Premaxilla}

The elements are identified as ?premaxillae based on their similarity to the Omphalosaurus cf., O. nevadanus specimen MBG 1500 (Sander \& Faber, 2003; Wintrich et al., 2017; pers. obs. CPE). PMO 229.922 (Fig. 3B) is the most complete element, while PMO 229.921 preserves only the posterior half (Fig. 3A). PMO 229.924 (Fig. 3C) and PMO 229.923 (Fig. 3D) miss the anterior and posterior ends and is heavily eroded. The ?premaxillae are less than half the size of those in the Omphalosaurus cf., O. nevadanus specimen MBG 1500 (Sander \& Faber, 2003) and relatively wider posteriorly than anteriorly compared to this specimen. Sander \& Faber (2003) stated that the elements interpreted as premaxillae in the Omphalosaurus cf., O. nevadanus specimen MBG 1500 could alternatively represent vomers or palatines, but that this is less likely as these elements appear toothless in the holotype of O. nevadanus (UCMP 8281).

In ventral view the ?premaxilla has an elongated triangular shape. The lateral surface is the anteroposteriorly longest and the posteromedial the shortest. PMO 229.922 (Fig. 3B4) differs from the others because it is curved posterior to the process in lateral view. The maximum dorsoventral height is encountered midway (Fig. 3B2), due to a dorsal triangular process as in Omphalosaurus cf., O. nevadanus, but this feature is also found in other Triassic ichthyopterygians (MBG 1500 pers. obs. CPE; Sander, 2000; Sander \& Faber, 2003). The process bears dorsoventrally oriented striations (Fig. $3 \mathrm{~A} 2$ ) and the lateral surface of the triangular process bears foramina that vary in number and placement between the specimens Fig. 3B4, A4). On both sides of the process is an embayment, which is deepest and anteroposteriorly shortest anterior to the process. It might represent the dental laminae (Fig. 3B2), or the posterior one (Fig. 3A2, B2) might have contributed to the external naris. On the dorsal surface are one foramen posterior to and one lateral to the triangular process in dorsal view (Fig. 3A3, B3 \& D3). An anteroposteriorly oriented ridge runs along the lateral surface in dorsal view (Fig. 3B3). The lateral surface bears radiating striations (Fig. 3C3). A narrow groove runs parallel to the ventral margin (Fig. 3A4, B4).

The element has two tooth-bearing surfaces, interpreted as the ventral and medial. The anterior half of the ventral surface is convex and bears tooth crowns in various states of wear (Fig. 3B1, B2 \& B4). A convex tooth-bearing ventral surface was also described for Omphalosaurus cf., O. nevadanus (MBG 1500 pers. obs. CPE). Posteriorly the teeth are located only along the lateral margin in PMO 229.922 (Fig. 3B1) while in PMO 229.921 (Fig. $3 \mathrm{~A} 1)$ the teeth cover the entire posteroventral surface. The tooth-bearing ventral surface, including the slopes towards the medial and posteromedial sides, is the only finished surface of the element (Fig. 3B1, B2), while the other surfaces show unfinished porous bone, lacking periosteum for cover of the outer surface, similar to Omphalosaurus cf., O. nevadanus (MBG 1500 pers. obs. CPE; Sander \& Faber, 2003). Erosion of finished surfaces is a possible reason, but is less likely as two specimens show the same feature.

\section{?Dentary}

Five massive tooth-bearing elements share some common morphological features, and are described together (Figs. $4 \& 5$ ). They have a concave dorsal surface with a triangular outline in dorsal view and teeth mainly located along the symphysis. The anterior surface bears a single tooth directed anteriorly and a process ventral to this (Fig. 4B). In medial view the replacement teeth are visible in the symphysis (Figs. 4B \& 5A2). The most complete element, PMO 229.916 (Fig. 4), is identified as a dentary based on its resemblance to the dentaries in the Omphalosaurus cf., O. nevadanus specimen MBG 1500 (pers. obs. CPE) and the Omphalosaurus nevadanus holotype (UCMP 8281, pers. obs. CPE). The other four elements are identified as ?dentaries. PMO 229.917 (Fig. 5) is complete but heavily weathered; PMO 229.919 (Fig. 5C) misses the anterior and posterior portions, while PMO 229.918 (Fig. 5A) and PMO 229.920 (Fig. 5B) preserve the anteriormost portion only. All of the elements are smaller than the dentaries of the Omphalosaurus cf., O. nevadanus specimen MBG 1500 Sander \& Faber (2003) (Electronic Supplement A).

PMO 229.916 (Fig. 4) is relatively slender, as the dentary in the Omphalosaurus cf., O. nevadanus MBG 1500 specimen and the holotype of Omphalosaurus nevadanus (UCMP 8281; CPE, pers. obs.), but with a slightly wider posteriormost portion. The anterior portion of $\mathrm{PMO}$ 229.916 is rounded in dorsal view. The posteromedial side 


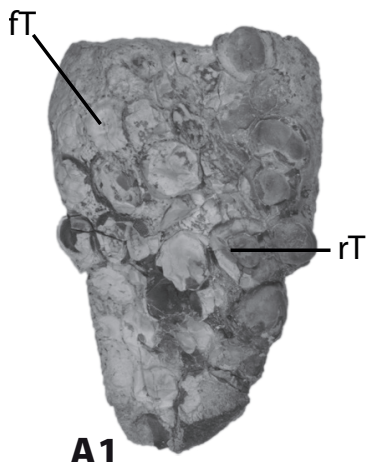

A1

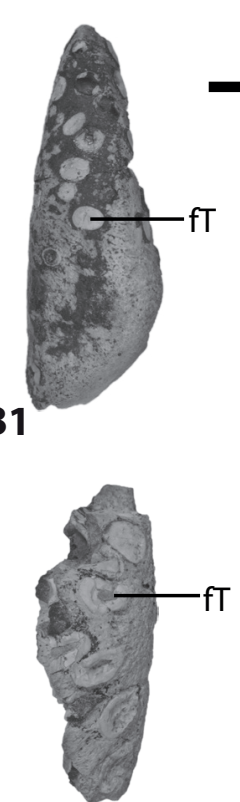

C1

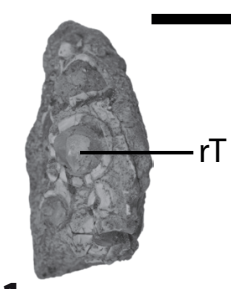

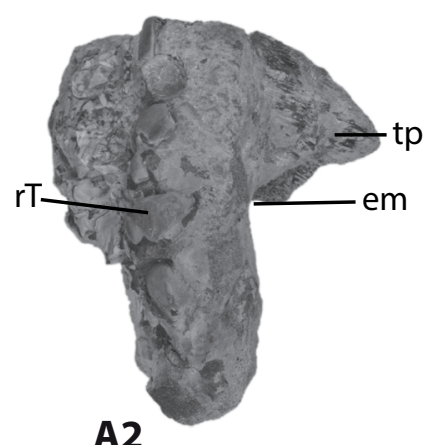

A2

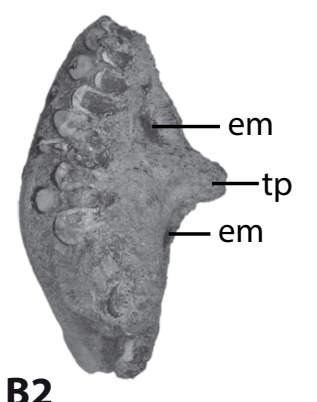

B2

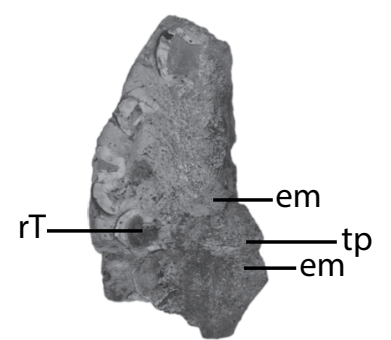

C2

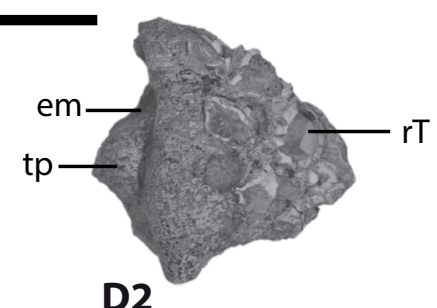

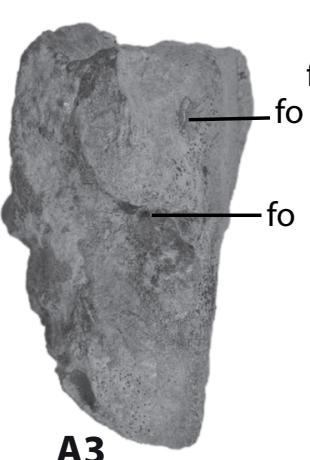

A3

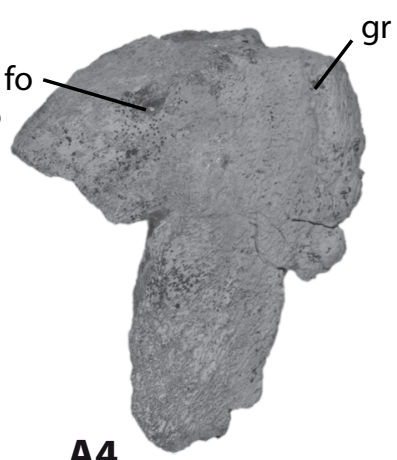

A4

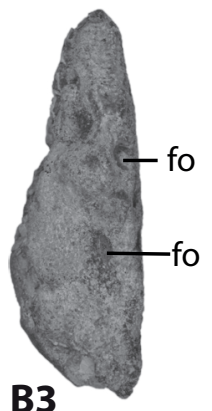

B3
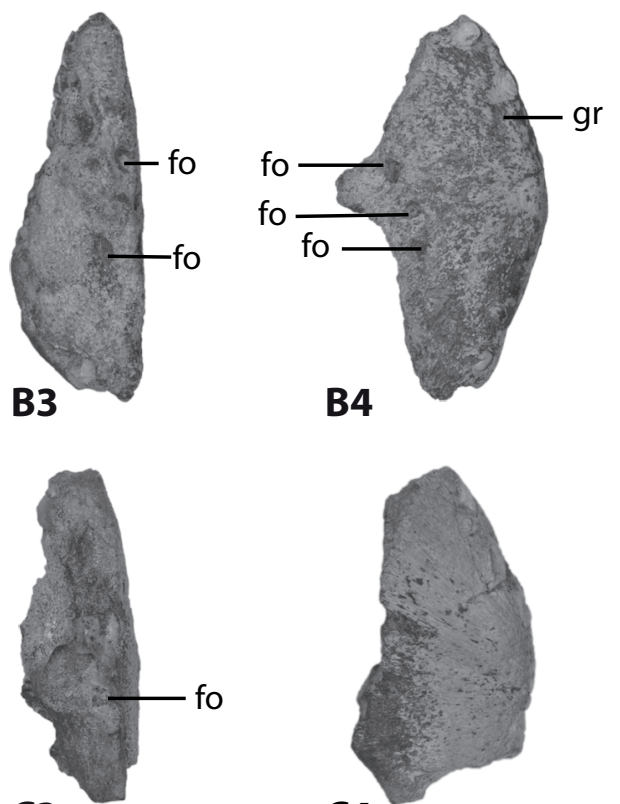

C3

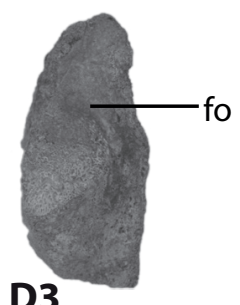

C4

B4
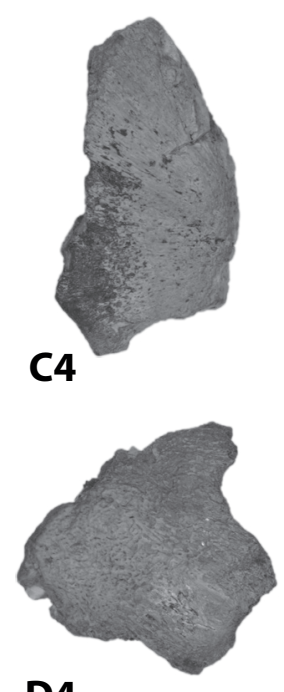

Figure 3. ?Premaxillae of Omphalosaurus sp. from Marmierfjellet (Spathian). (A) PMO 229.921, left ?premaxilla. A1 - Ventral view, A2 Medial view, A3 - Dorsal view, A4 - Lateral view. (B) PMO 229.922, left ?premaxilla. B1 - Ventral view, B2 - Medial view, B3 - Dorsal view, B4 - Lateral view. (C) PMO 229.924, left ?premaxilla. C1 - Medial view, C2 - Dorsal view, C3 - Lateral view. (D) PMO 229.923, right ?premaxilla. D1 - Medial view, D2 - Dorsal view, D3 - Lateral view. Scale bar $=20 \mathrm{~mm}$. Anterior is to the top for all photographs. Abbreviations: em embayment, fo - foramina, $f T$ - functional teeth, $g r$ - groove, $r T$ - replacement teeth, tp - triangular process.

has a $50^{\circ}$ angle from the posterior portion of the symphysis towards the posteriormost end. On the ventral surface (Fig. $4 \mathrm{C})$, a massive ridge runs from the anterior tip posteriorly along the lateral margin. Posteriorly this ridge slopes into a groove, dorsoventrally deepest at the posteriormost end. The dorsal portion of the medial surface is smooth with dorsoventrally oriented striations, assumed to be vascular canals (Fig. 4B). This feature is also found in PMO 229.918 (Fig. 5A2). The teeth in PMO 229.916 are poorly preserved, and are mainly located irregularly along the symphysis and medioposterior surface.
PMO 229.917 is wider mediolaterally and shorter anteroposteriorly than PMO 229.916 and the anteroposterior length of the symphysis is longer. In dorsal view, PMO 229.917 has a convex lateral margin. PMO 229.918 (Fig. 5A) and PMO 229.920 (Fig. 5B) are narrower and more pointed anteriorly than the other specimens, and with larger teeth and anterior dorsoventral height. In PMO 229.918 and PMO 229.920 the lateral surface has an angle to the symphysis. The dentary widens mediolaterally posteriorly, until the end of the symphysis where the width is at a maximum 

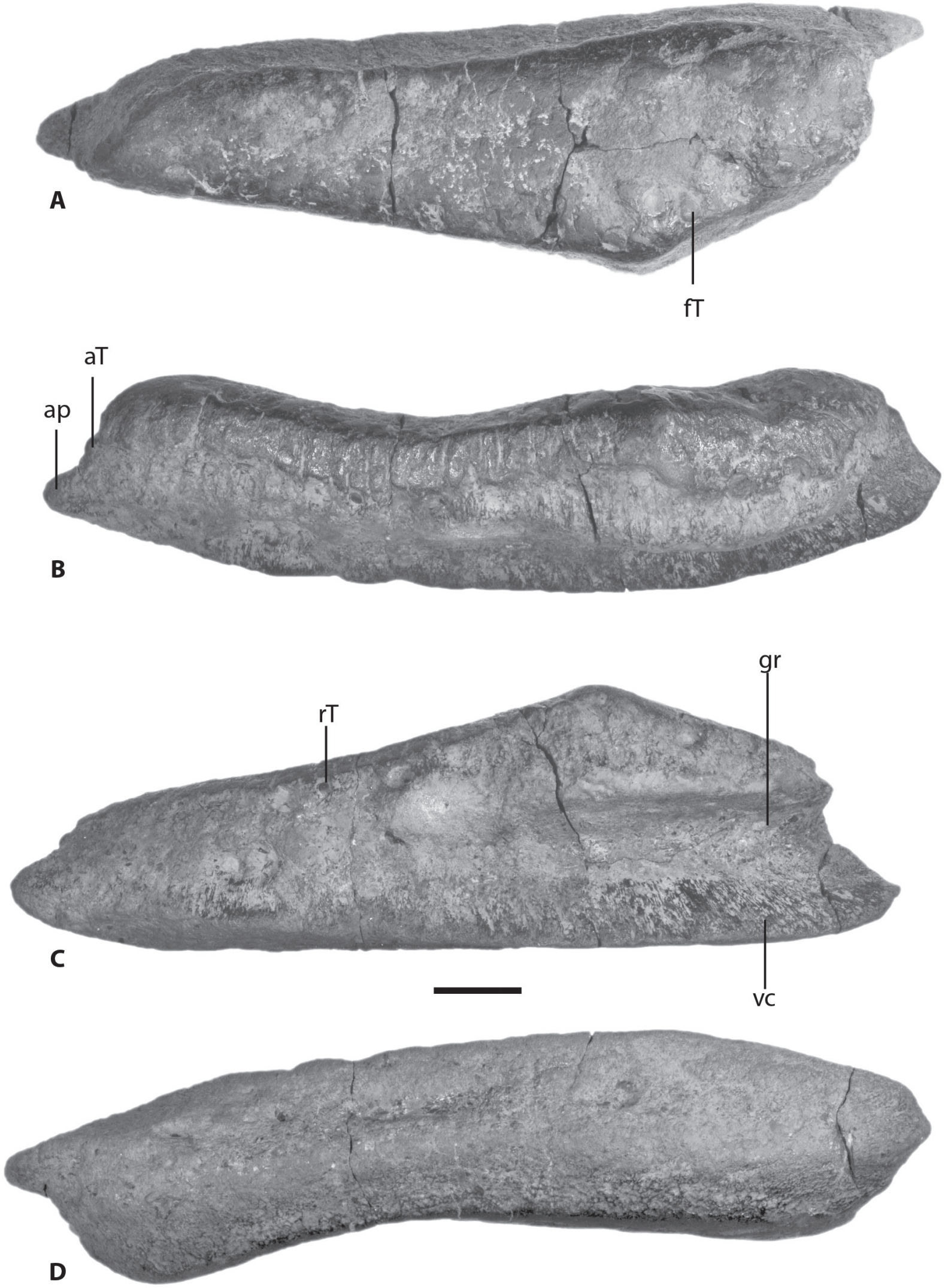

Figure 4. Right dentary (PMO 229.916) of Omphalosaurus sp. from Marmierfjellet (Spathian). (A) Dorsal view. (B) Medial view. (C) Ventral view. (D) Lateral view. Scale bar $=20 \mathrm{~mm}$, anterior is to the left. Abbreviations: ap - anterior process, aT - anteriormost tooth, fo - foramina, $f T$ - functional teeth, $g r$-groove, $r T$ - replacement teeth, $v c$-vascular canal. 


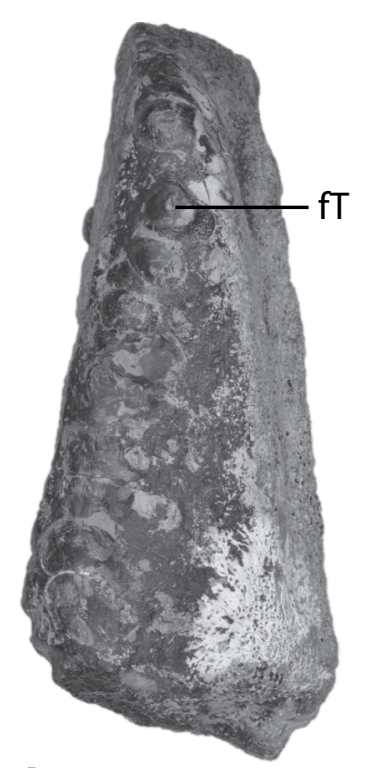

A1

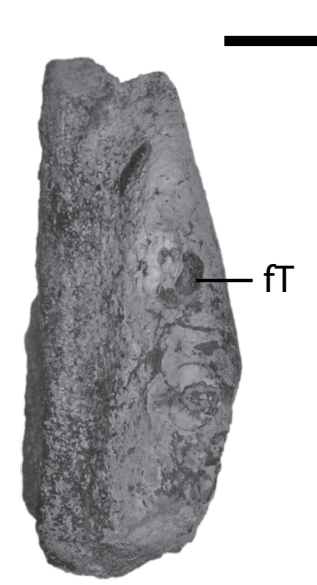

B1

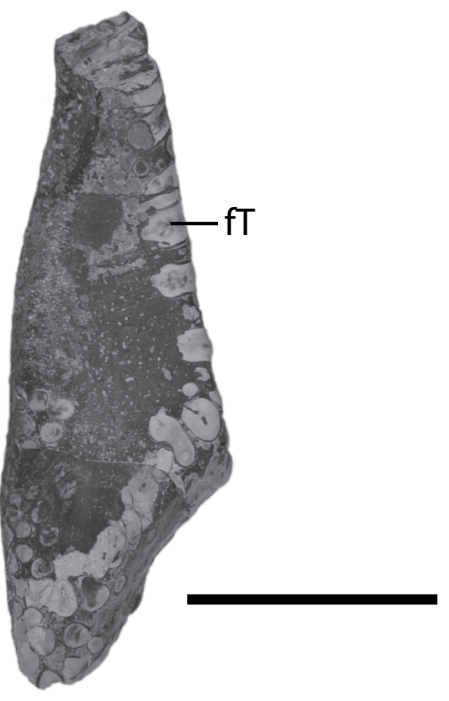

C1

C2

A2

B2
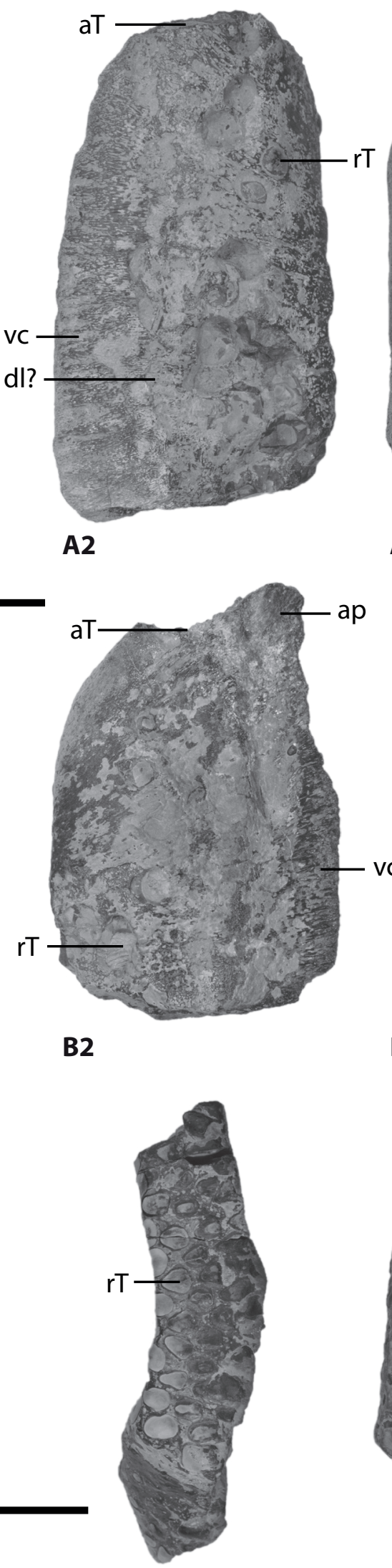

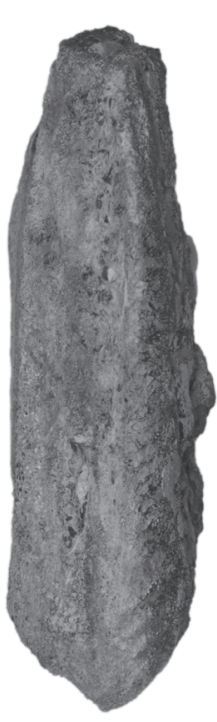

A3

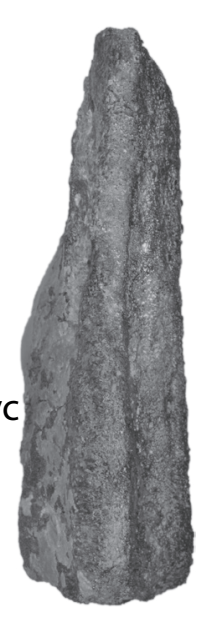

B3

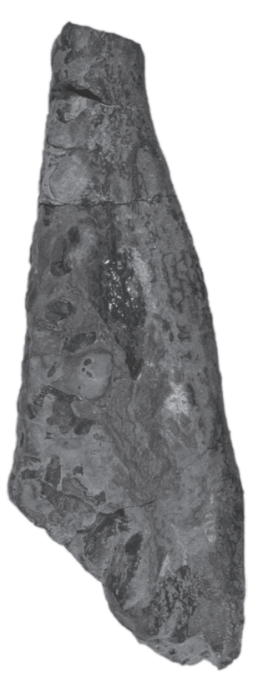

C3

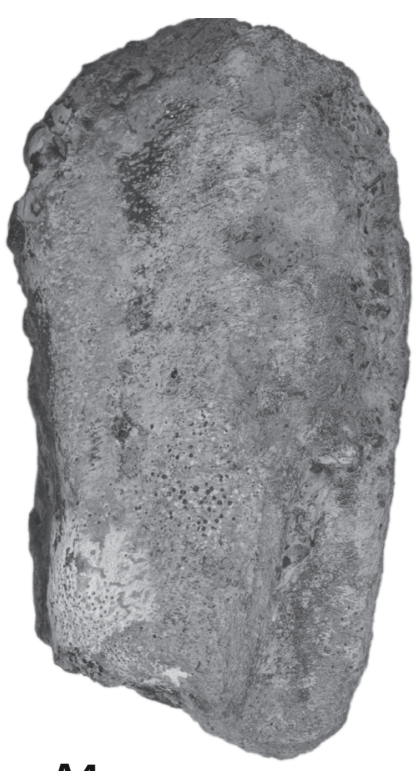

A4

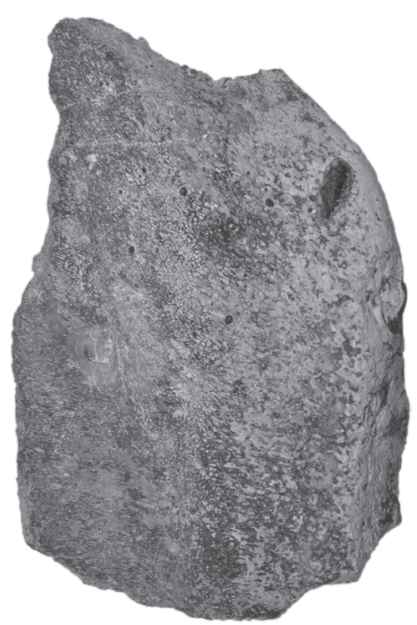

B4

Figure 5. ?Dentaries of Omphalosaurus sp. from Marmierfjellet (Spathian). (A) PMO 229.918, right ?dentary. A1 - Dorsal view, A2 - Medial view, A3 - Ventral view, A4 - Lateral view. (B) PMO 229.920, left ?dentary. B1 - Dorsal view, B2 - Medial view, B3 - Ventral view, B4 Lateral view. (C) PMO 229.919, left ?dentary. C1 - Dorsal view, C2 - Medial view, C3 - Ventral view, C4 - Lateral view. Scale bar $=20 \mathrm{~mm}$, anterior is to the top. Abbreviations: ap - anterior process, aT - anterior tooth, dl - dental laminae, $f T$ - functional teeth, $r T-r e p l a c e m e n t$ teeth, vc-vascular canals. 

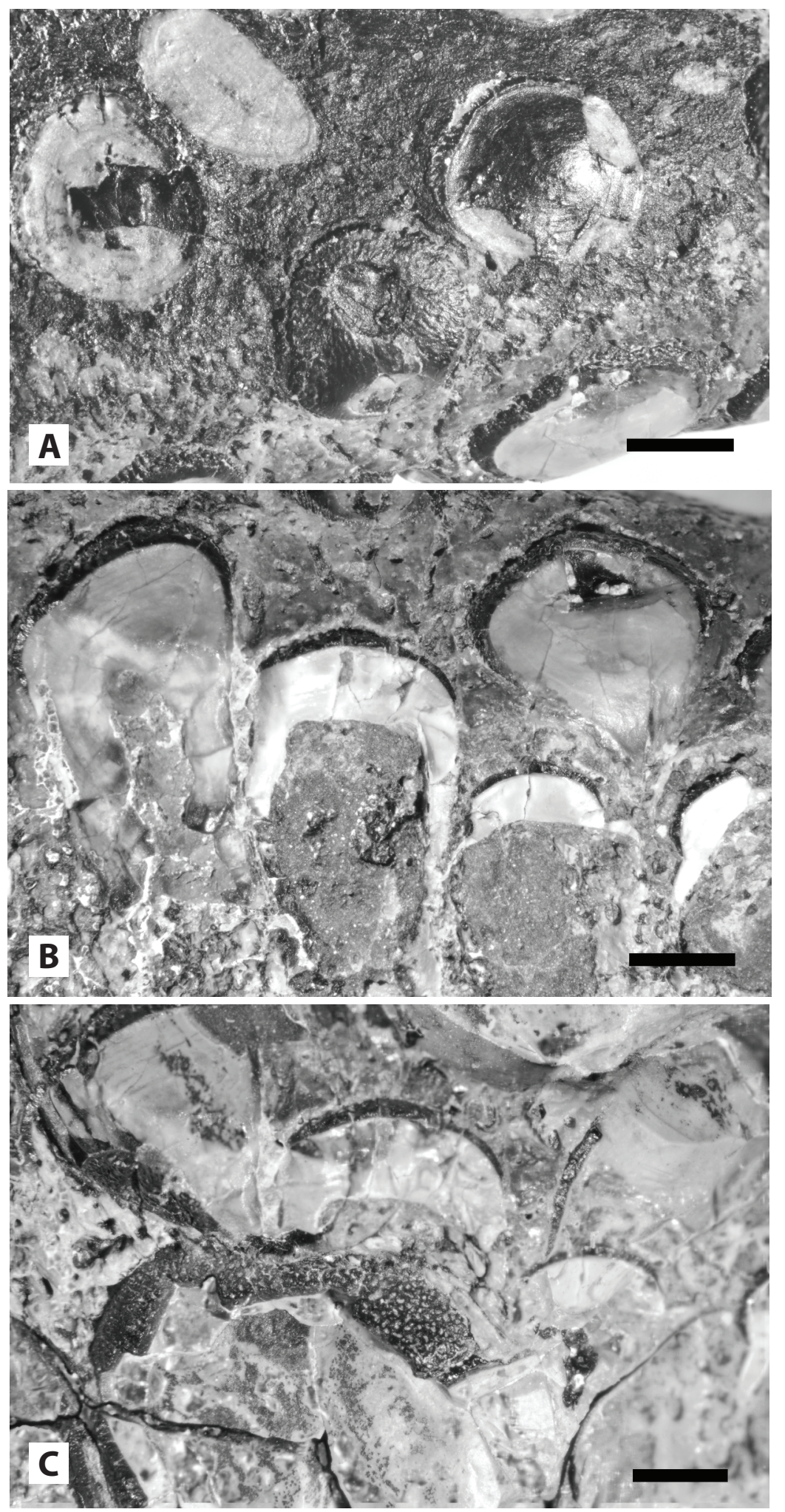

Figure 6. ?Premaxillary teeth of Omphalosaurus sp. from Marmierfjellet (Spathian). (A) Occlusal view PMO 229.922. (B) Medial view PMO 229.917. (C) Occlusal view PMO 229.921. Scale bar $=2 \mathrm{~mm}$. Abbreviations: $D$ - dentine, E-enamel, Pc-pulp cavity.

perpendicular to the symphysis. PMO 229.919 (Fig. 5C) is smaller, and compared to PMO 229.916 (Fig. 4) the lateral surface is dorsoventrally shorter. Its medial surface is smooth with stacked teeth, which differs from the other specimens.

\section{Dentition}

The premaxillary teeth can be observed on the occlusal surface and in medial view of the premaxillae (Figs. 4-6). The teeth are irregularly spaced and densely packed anteriorly, spreading out along the medial and lateral 
margins posteriorly. In ventral view of PMO 229.922 (Figs. 3B \& 6A) most of the teeth are only observable in cross-section of the lower crown. The enamel cap, preserved in two teeth, has an irregular surface structure. The crowns of the teeth show some shape variation, but a majority are rounded (e.g., PMO 229.922; Fig. 6A). Rounded crowns are in addition to Omphalosaurus found in Tholodus and Xinminosaurus (Sander, 1999; Arkhangelsky et al., 2016) and in the anterior portion of the premaxilla in Gulosaurus (Cuthbertson et al., 2013). In contrast, the Early Triassic genera Grippia, Utatsusaurus, Chaohusaurus, Thaisaurus and Parvinatator have cone-shaped crowns (Shikama et al., 1978; Mazin et al., 1991; Maisch \& Matzke, 2000; Zhou et al., 2017). The rounded tooth crowns of Tholodus and Xinminosaurus differ from Omphalosaurus especially in the enamel microstructure (Sander, 1999; Arkhangelsky et al., 2016).

The diameter of the lower tooth crowns in the premaxilla PMO 229.922 is $2-5 \mathrm{~mm}$, and the larger teeth are located between the medial and lateral surface anteriorly and on the medial surface. PMO 229.922, from the Lower Saurian niveau, has fewer and more widely spaced teeth than the premaxillae collected from the Grippia niveau. It has very few teeth on the posterior part of the occlusion surface, compared to PMO 229.921 that mainly have teeth on the posterior part of the occlusion surface. The dental lamina is visible in medial view of the premaxilla PMO 229.922 (Fig. 3B2). The teeth located close to the dental laminae have a dorsoventrally tall pulp cavity filled with dentine close to the occlusion surface (Fig. $6 \mathrm{~B})$. The replacement teeth are globular in lateral view. In PMO 229.921 (Fig. 6C) only a small portion of the occlusion surface is preserved, with teeth in various states of wear. In this specimen the teeth are more densely packed than in PMO 229.922. The preserved part of the enamel along the margins of the crown has the typical "orange-peel structure" of Omphalosaurus (Sander \& Faber, 2003) (Fig. 6B). The cross section of the crowns has a maximum diameter of $10 \mathrm{~mm}$ (PMO 229.921), less than the Omphalosaurus cf., O. nevadanus specimen (MBG 1500; 7-21 mm) (Sander \& Faber, 2003), and the premaxilla itself is also significantly smaller.

In the ?dentary PMO 229.918, the bases of the densely packed crowns at the occlusal surface are irregular. In this specimen some of the replacement teeth are visible in medial view, where the dentine replaces the pulp cavity towards the occlusion surface (Fig. 7C), as described for the premaxillary teeth. The tooth crowns are preserved in a few teeth anteriorly and are rounded with the typical "orange-peel structure" of Omphalosaurus (Sander \& Faber, 2003) (Fig. 7B). The maximum diameter of the crowns varies between 6 and $11 \mathrm{~mm}$, which is similar to the Omphalosaurus cf., O. nevadanus specimen (3.5 - 11 $\mathrm{mm}$ ). One single tooth is anteriorly directed (Fig. 7A). In the ?dentary PMO 229.919, the teeth on the dorsal surface are located along the symphysis, the medioposterior margin and the posterior half of the lateral margin. The teeth along the symphysis are relatively large compared to other specimens, and occur in one row (Fig. 5C1). The teeth of Omphalosaurus has been described as occurring in rows on the dentary and premaxilla (Merriam, 1906; Merriam \& Bryant, 1911; Wiman, 1916; Mazin, 1986), but distinct rows has not been confirmed, and the teeth are normally irregularly packed along the symphysis (Wiman, 1910; Motani, 2000; Sander \& Faber, 2003).

Crushing teeth on the posterior part of the dentary is observed in dentary PMO 229.919, while Xinminosaurus has rounded crushing teeth on the maxilla and posterior part of dentary (Jiang et al., 2008). In dorsal view, PMO 229.919 has a higher density of small teeth in the posteriormost portion than the other specimens. The teeth on the posterior half of the lateral margin in dorsal view of PMO 229.919 are even smaller than the more posterior teeth, and irregularly and densely packed. The teeth of the dentary PMO 229.919 are all visible as cross sections of the lower crown on the occlusal surface, as irregular elongated, egg-shaped and rounded. The diameter of the tooth crowns is $1-5 \mathrm{~mm}$, where the maximum represents the very elongated ones. In medial view densely packed and oval replacement teeth are visible. An interesting feature of the medial surface of PMO 229.919 is that the replacement teeth are worn in a similar manner to the teeth observed on the occlusal surface. This is the same feature that was described of the medial surface of premaxilla PMO 229.922 (Fig. 3B2) as well as the dorsal part of the medial surface of dentary PMO 229.916 (Fig. 4B).

\section{Ichthyopterygia Owen, 1840 Ichthyopterygia indet.}

\section{Vertebrae}

Measurements of the centra given in Electronic Supplement A, table 1. A Grippia cervical vertebra is pictured in Fig. 8 for comparison.

The atlas (Fig. 9A) has a convex, nearly circular anterior face and deeply concave posterior face, as in the Omphalosaurus cf., O. nevadanus specimen (MBG 1500) (Sander \& Faber, 2003). The H/L of PMO 229.903 is 1.73, while it is 2.07 in the Omphalosaurus cf., O. nevadanus specimen (Sander \& Faber, 2003). The anterior face shows a Y-mark located in the centre (Fig. 9A1), where it met the occipital condyle. The surface of the atlas is very porous, but whether this is due to lack of finished bone or erosion is uncertain. The facet for the atlantar arch is preserved on the dorsal surface while the rib facets are not preserved.

Cervical vertebrae are identified by having separate parapophyses and diapophyses. The diapophysis is confluent with the neural arch. The parapophyses and diapophyses are confluent with the anterior rim of the 

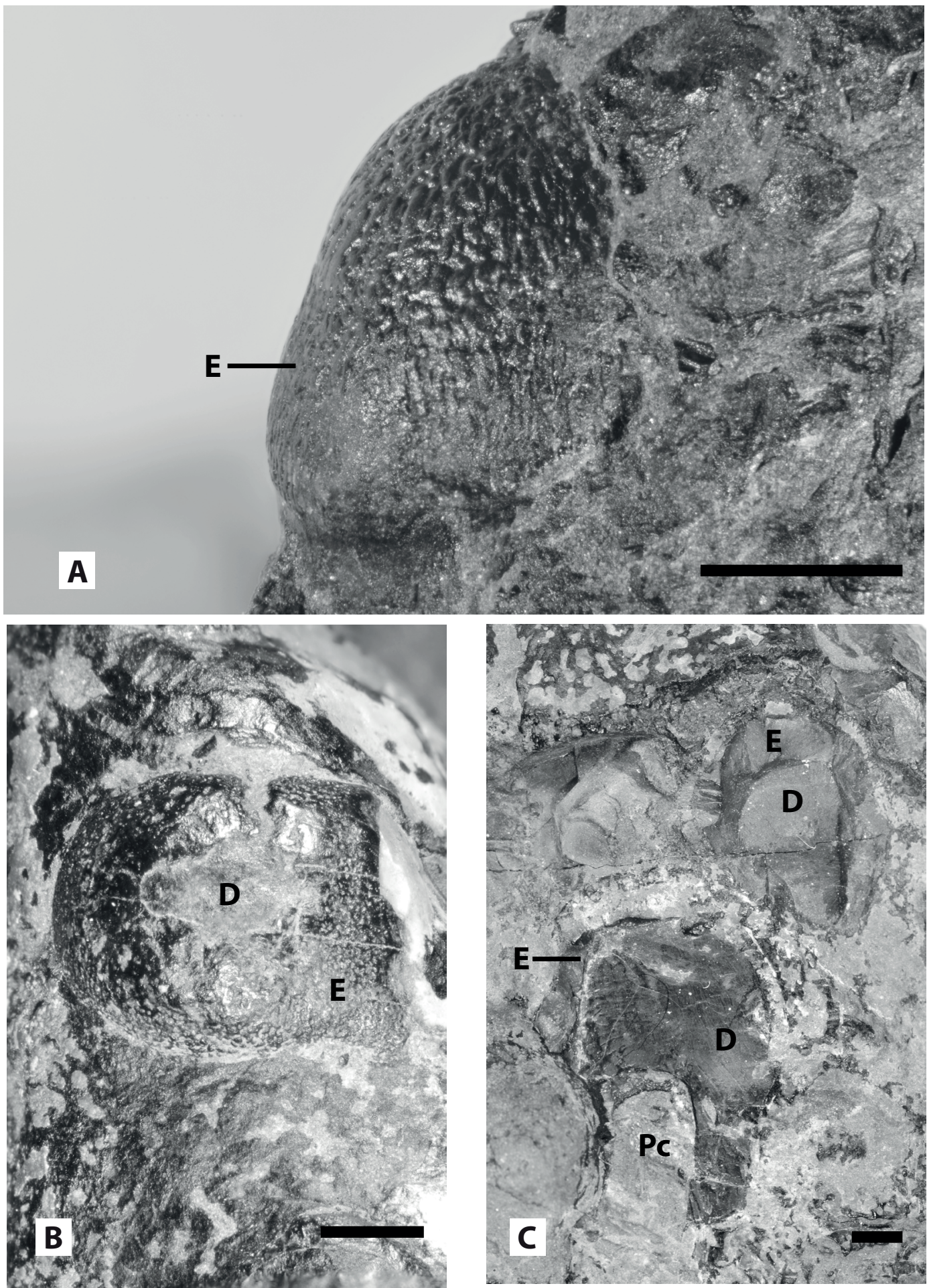

Figure 7. ?Dentary teeth of Omphalosaurus sp. from Marmierfjellet (Spathian). (A) anteriormost tooth in lateral view of PMO 229.916. (B) occlusal view PMO 229.918. (C) medial view PMO 229.918. Scale bar $=2 \mathrm{~mm}$. Abbreviations: $D-$ dentine, $E-$ enamel, Pc - pulp cavity.

centrum, as in the cervical vertebrae of Grippia (Fig. 8B) and Gulosaurus (Brinkman et al., 1992; Cuthbertson et al., 2013). The diapophysis is continuous with the facet for the neural arch as well as the posterior margin dorsally. In PMO 229.905 (Fig. 9C3) the parapophysis is reduced and situated closer to the diapophysis along the anterior rim of the centrum compared to the others.
In dorsal view the floor of the neural canal is mediolaterally narrow and hourglass-shaped. The outline in anterior view (Fig. 9B, C) is pentagonal, mediolaterally wider than anteroposteriorly high and best preserved in PMO 229.904 (Fig. 9B1). In posterior view the outline is shield-shaped (Fig. 9B2, C2), as the cervical vertebrae of Grippia (Fig. 8). The ventral surface has a pronounced 

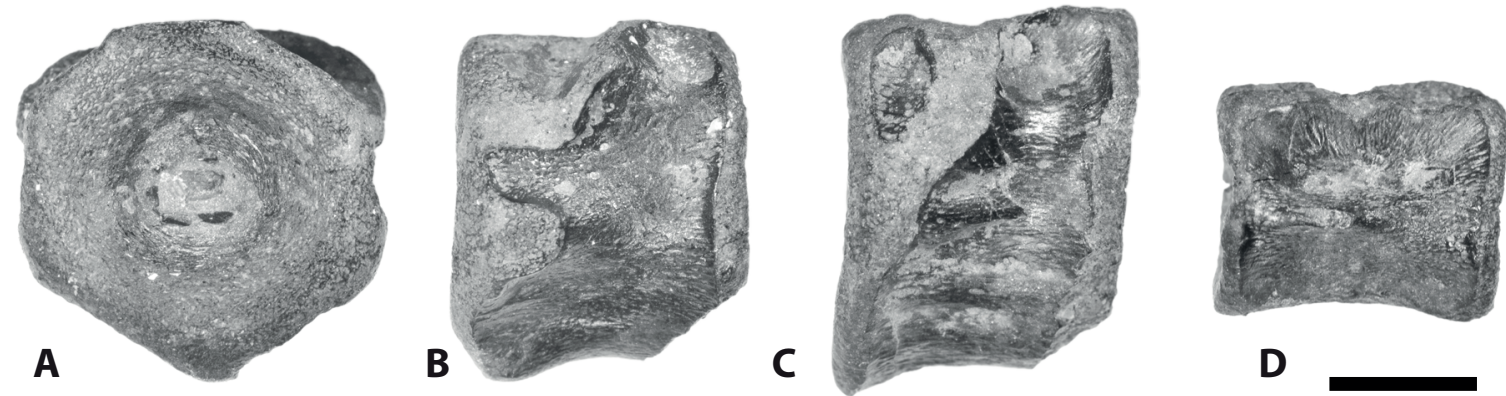

Figure 8. Vertebrae of Grippia from the Grippia bonebed, Marmierfjellet (Spathian). (A) Cervical vertebra PMO 230.211 in anterior view. (B) Cervical PMO 230.211 lateral view. (C) Dorsal PMO 230.212 lateral view. (D) Caudal PMO 230.213 lateral view. Scale bar $=5 \mathrm{~mm}$.

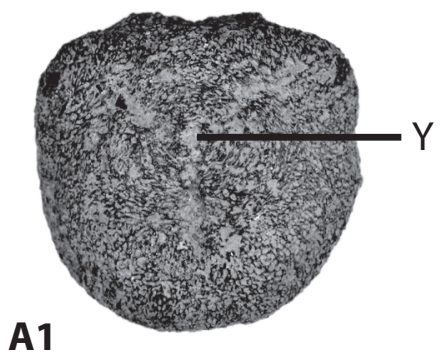

A1

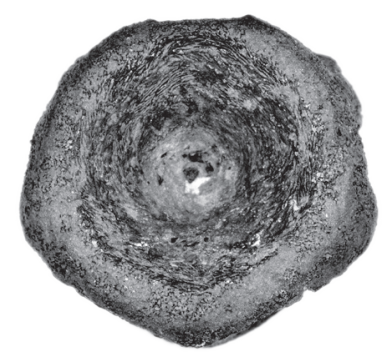

B1

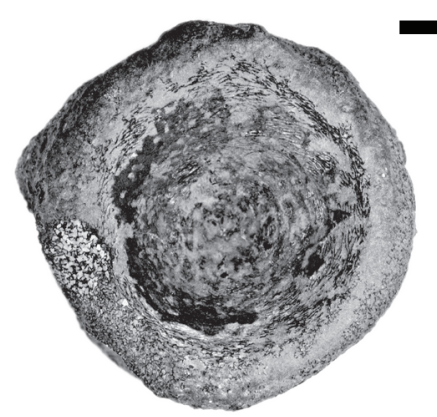

C1
A2
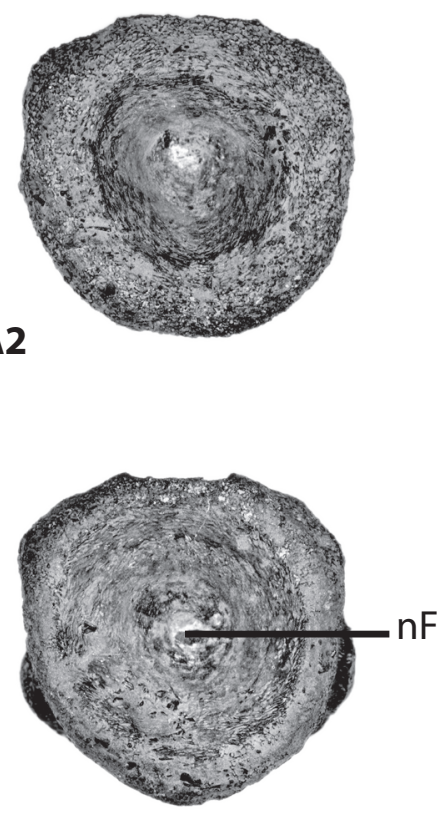

B2

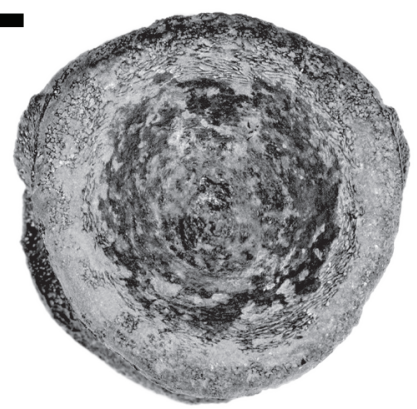

C2
A3
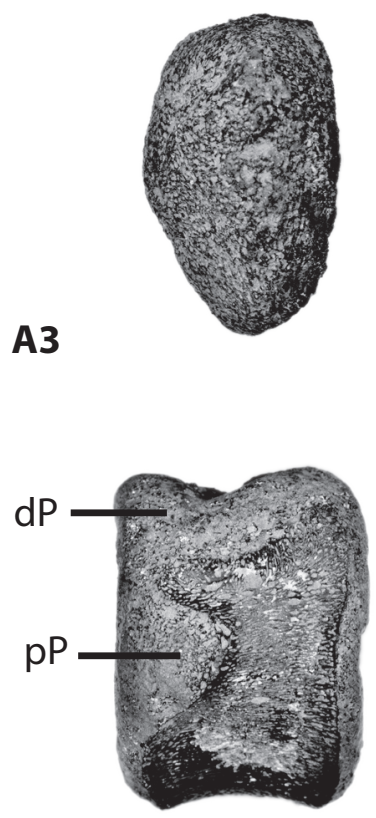

B3

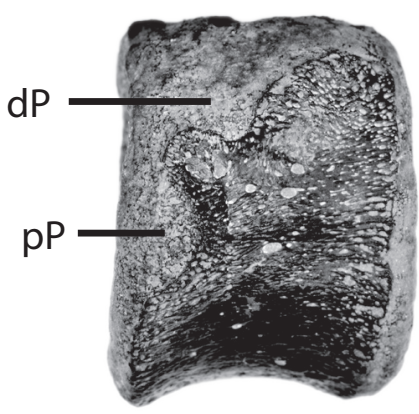

C3

Figure 9. Cervical vertebrae of Ichthyopterygia indet. from Marmierfjellet (Spathian). (A) PMO 229.903, atlas. A1 - Anterior view, A2 Posterior view, A3 - Lateral view. (B) PMO 229.904. B1 - Anterior view, B2 - Posterior view, B3 - Lateral view. (C) PMO 229.905. C1 Anterior view, C2 - Posterior view, C3 - Lateral view. Scale bar $=10 \mathrm{~mm}$, anterior is to the left for photographs in lateral view. Abbreviations: $d P$ - diapophysis, $n F$ - notochordal foramen, $p P$ - parapophysis, $Y$ - Y-mark.

keel, a feature also present in Grippia (Fig. 8). In the holotype of Omphalosaurus nevadanus (UCMP 8281) two vertebrae articulated to the skull were interpreted as anterior cervicals (Merriam, 1906). They are deeply amphicoelous and nearly circular in cross section (Mazin, 1986; but see Motani 2000), similar to the material described herein. Centra of Gulosaurus and Grippia are also deeply amphicoelous, with double rib articulation in the cervicals (Brinkman et al., 1992; Cuthbertson et al., 2013).

The dorsal vertebrae are rounded in anterior and posterior view and anteroposteriorly short. Several vertebrae possess a periosteum that is "wrinkled". The 

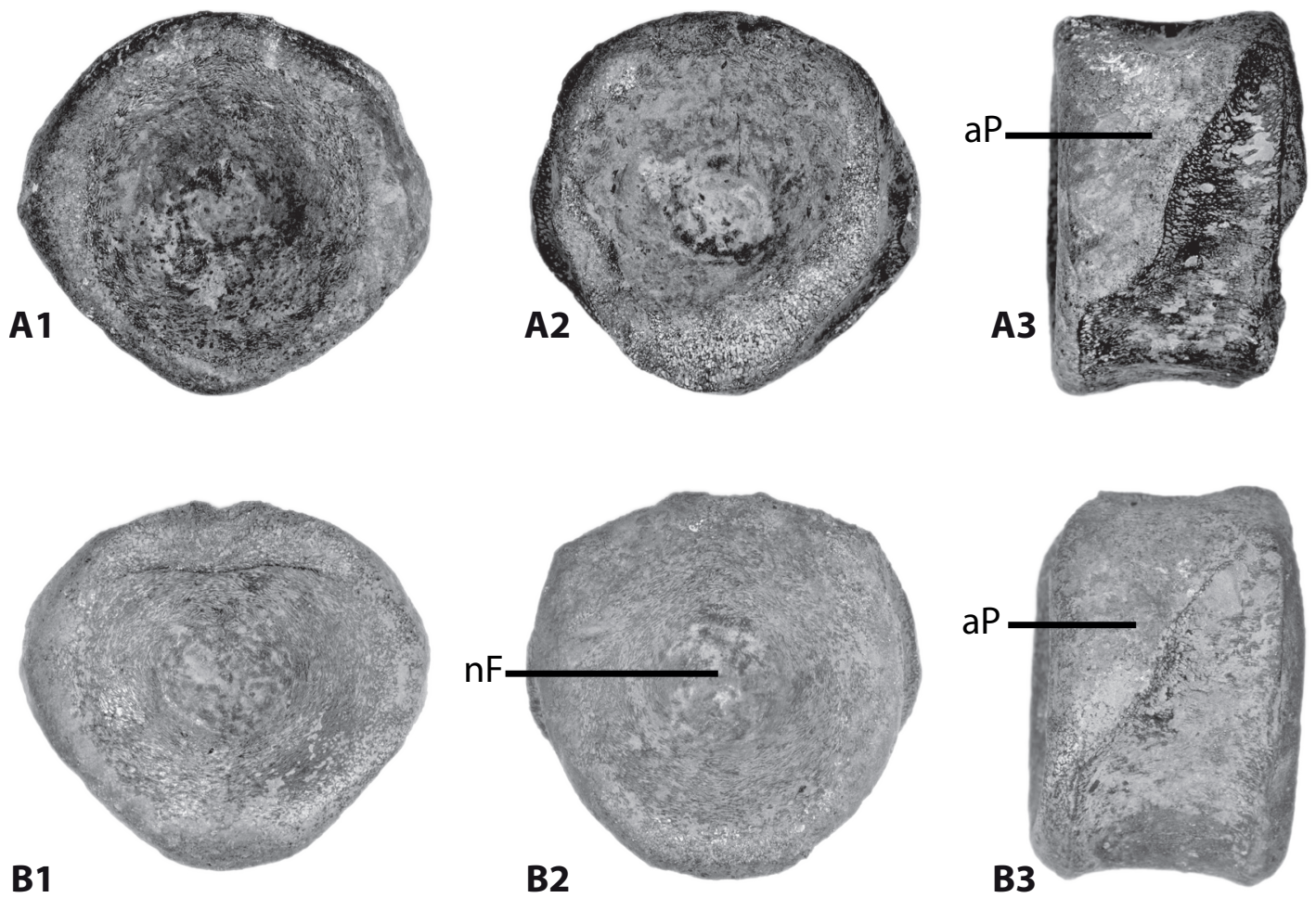

C1
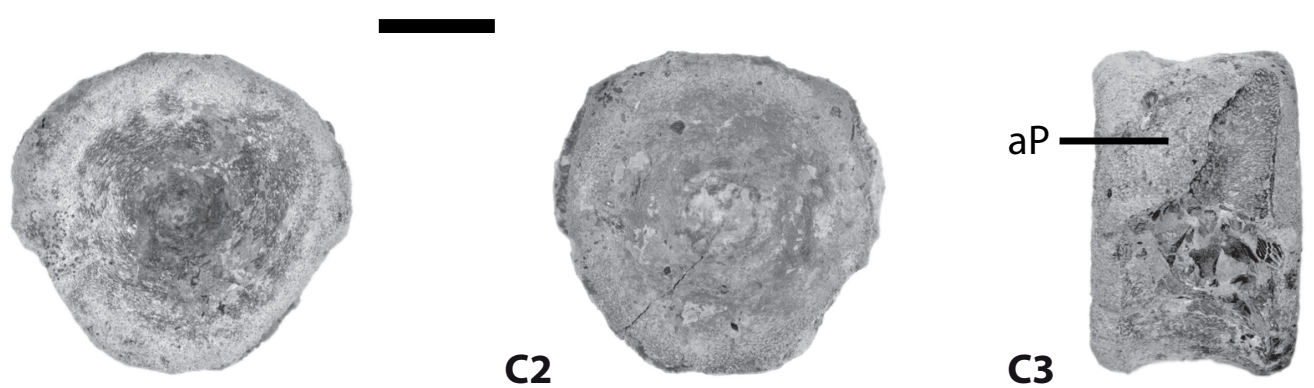

Figure 10. Dorsal vertebrae of Ichthyopterygia indet. from Marmierfjellet (Spathian). (A) PMO 229.906. A1 - Anterior view, A2 - Posterior view, A3 - Lateral view. (B) PMO 229.907. B1 - Anterior view, B2 - Posterior view, B3 - Lateral view. (C) PMO 229.908. C1 - Anterior view, C2 - Posterior view, C3 - Lateral view. Scale bar $=10 \mathrm{~mm}$, anterior is to the left for photographs in lateral view. Abbreviations: aP - apophysis, $n F-$ notochordal foramen.

anterior dorsal vertebrae have a single, large apophysis (Fig. 10A3, B3 \& C3) and are more circular in anterior view than the cervical vertebrae, but similar in being wider than high. A single large apophysis in anterior dorsal vertebrae is also known for Cymbospondylus (Sander, 1992), but in the centra described here the apophysis is widest in the dorsal portion, while it is equally narrow for its entire length in Cymbospondylus. In lateral view the apophysis is confluent with the anterior margin of the centrum, as well as with the dorsalmost portion of the posterior margin where the periosteal bone posterior to the apophysis ends. The centra are deeply amphicoelous and the posterior face has the same shield-shape as the cervical vertebrae. The different peripheral shape of the anterior and posterior face occurs only in the cervical and anterior dorsal vertebrae. It gives an anterior face that is wider than high, while the posterior face is always higher than wide. The mediolaterally widest part of the vertebra in anterior view is midway between the dorsal and ventral margins for PMO 229.906 (Fig. 10A1), but for PMO 229.907 (Fig. 10B1) and PMO 229.908 (Fig. 10C1) the widest part is more dorsally situated. The Omphalosaurus cf., O. nevadanus specimen (MBG 1500) dorsal vertebra has H/L >1.3 (Sander \& Faber, 2003), slightly less than those described here. The posterior dorsal vertebrae have a single dorsoventrally elongated facet covers the entire anterior margin of the centra. PMO 229.909 (Fig. 11A) is more circular in anterior and posterior view than the anterior dorsal vertebrae. The floor of the neural canal is elevated. The dorsal surface is more rounded than anterior dorsal vertebrae.

The anterior caudal vertebrae (Fig. 12) are recognized by being higher than wide, with a single articulation facet situated at the anterior margin, slightly ventral to the middle of the centra in lateral view. In PMO 229.913 (Fig. 12C) the articulation facet is small, while in PMO 229.914 (Fig. 12D) it is barely visible. The anterior caudal vertebrae are notochordal at the centre with the 

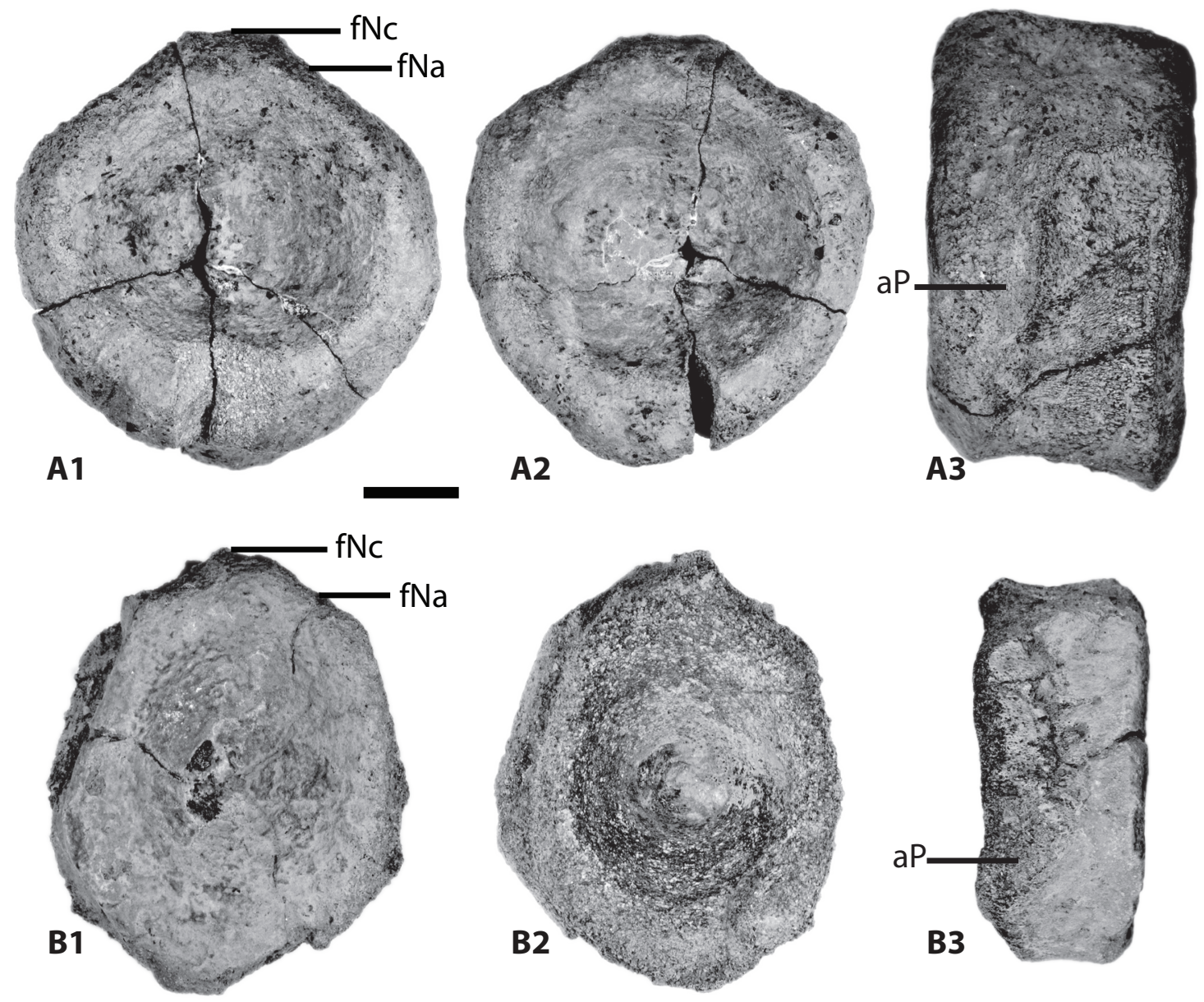

Figure 11. Posterior dorsal vertebrae of Ichthyopterygia indet. from Marmierfjellet (Spathian). (A) PMO 229.909. A1 - Anterior view, A2 Posterior view, A3 - Lateral view. (B) PMO 229.910. B1 - Anterior view, B2 - Posterior view, B3 - Lateral view. Scale bar $=10 \mathrm{~mm}$, anterior is to the left for photographs in lateral view. Abbreviations: aP - apophysis, $f \mathrm{Na}$-facet for neural arch, $f \mathrm{Nc}$ - floor of neural canal.

notochordal foramen clearly visible in anteroposterior view. PMO 229.911 is circular in anteroposterior view. PMO 229.912 (Fig. 12B) is hexagonal in shape. PMO 229.914 (Fig. 12D3) differs from the other centra by being wider dorsally than ventrally in lateral view. In dorsal view the floor of the neural canal is not flat as for the cervical vertebrae, but appears as a deep elongated embayment, with heightened ridges for articulation with the neural arches. The ventral surface is flat and lacks a keel.

The posterior caudal vertebrae (Fig. 13) have no apophysis. PMO 230.135 (Fig. 13A) has a dorsoventrally elongated hexagonal shape in anteroposterior view. Some centra are more oval, e.g., PMO 230.137 (Fig. 13C). PMO 230.138 (Fig. 13D) is anteroposteriorly thin in lateral view. In lateral view the anterior and posterior margin of the centra are prominent and are connected by an anteroposteriorly oriented ridge in the dorsoventral midpoint. There are facets for the neural arch on the dorsal surface (Fig. 14E1), and the floor of the neural canal is prominent. The ventral surface (Fig. 14E2) has a depression in the anteroposterior midpoint.

\section{Discussion}

The jaw elements are massive and display dome-shaped teeth without plicidentine, as in Omphalosaurus (Mazin \& Bucher, 1987; Sander \& Faber, 2003). Motani (1999) suggested plicidentine as a possible basal synapomorphy for the Ichthyopterygia, but plicidentine is not confirmed in Utatsusaurus (Shikama et al., 1978) and Parvinatator (Brinkman et al., 1992). The ?premaxillae are referred to Omphalosaurus based on a convex occlusion surface and a triangular ascending process in dorsal view (MBG 1500; Sander \& Faber, 2003). Three different morphologies of the dentaries are distinguished based on shape and organization of teeth, one from the Grippia niveau and two from the Lower Saurian niveau. The morphological differences could be due to different taxa, ontogenetic age or individual differences, a question that could be resolved in further work by using SEM for the tooth enamel. The groove described on the ventral surface of the dentary PMO 229.916 is most likely a suture for the more ventrally placed bones in the lower jaw. In the holotype of Omphalosaurus nevadanus (UCMP 8281, 
A1
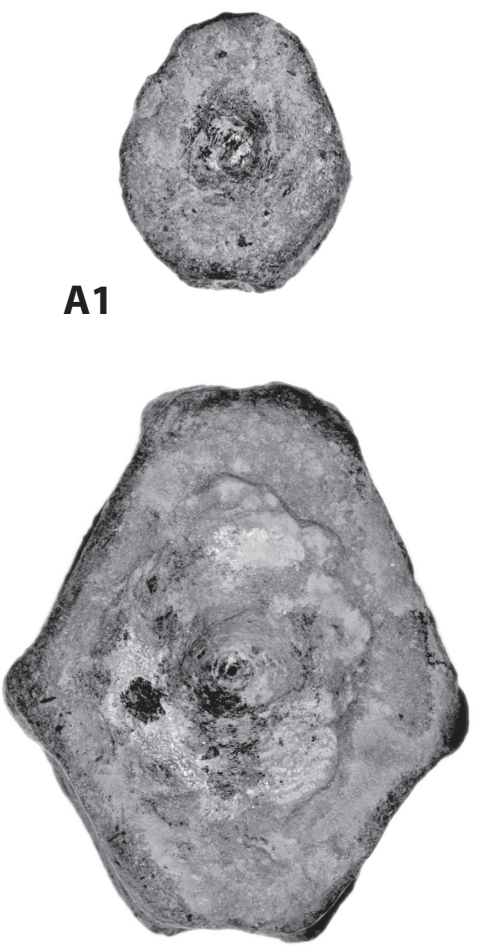

B1
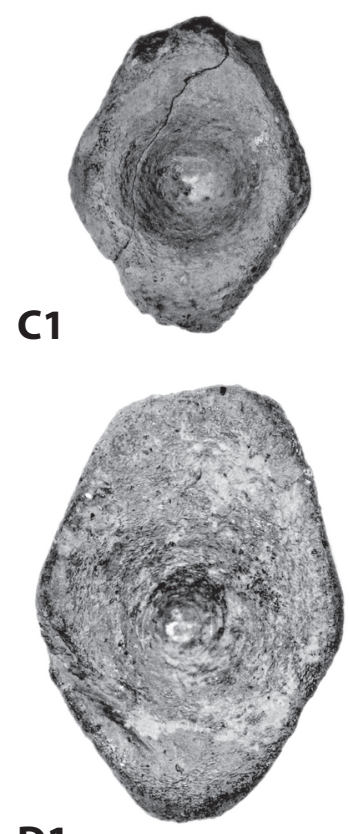

D1

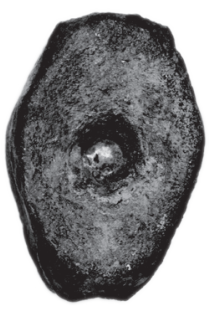

E1

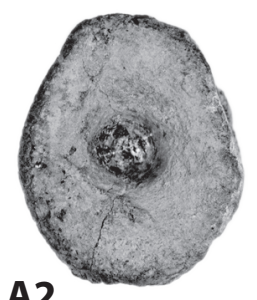

A2

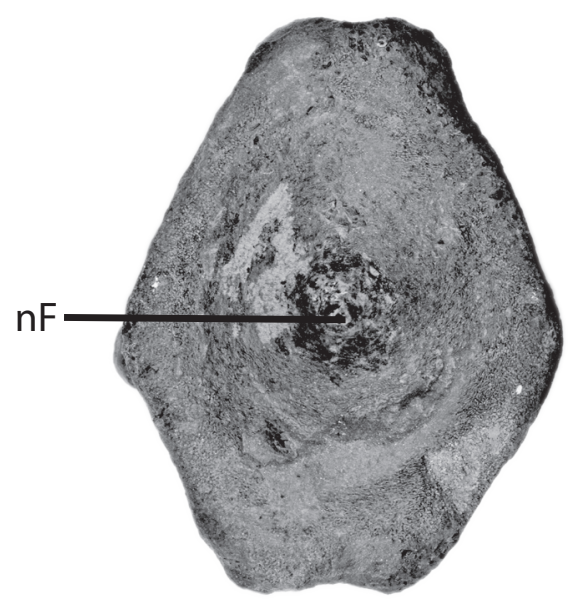

B2
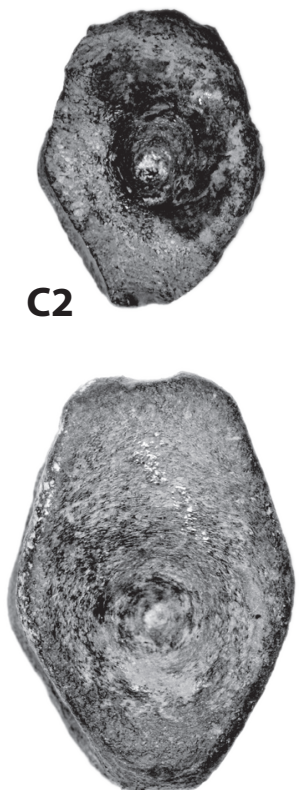

D2

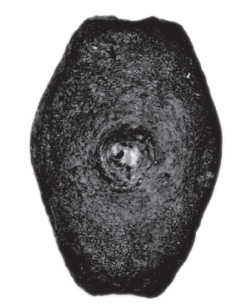

E2
A3

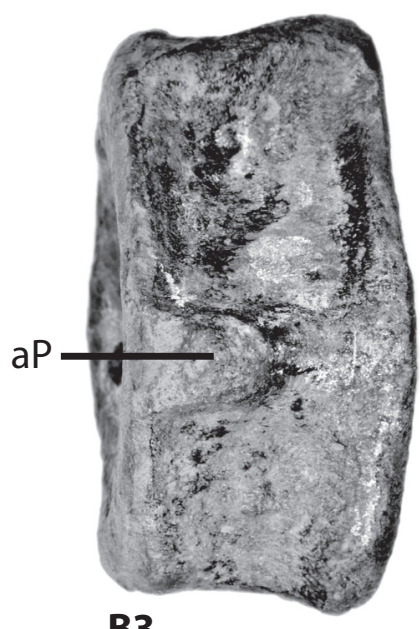

B3
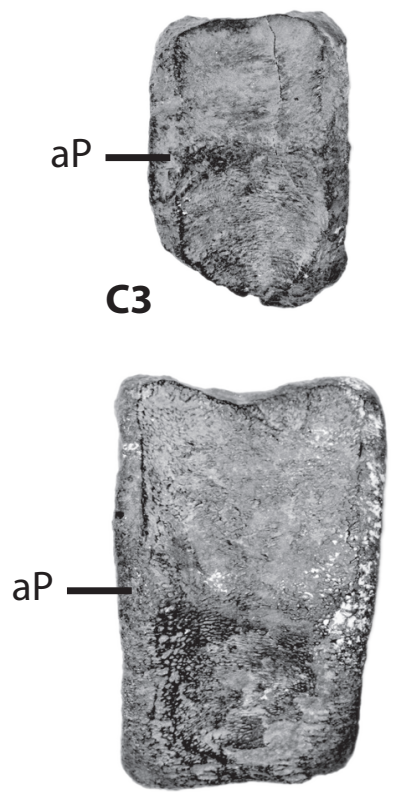

D3

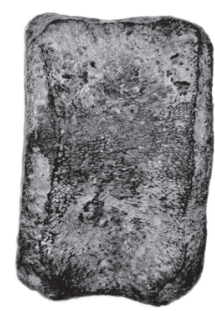

E3

Figure 12. Anterior caudal vertebrae of Ichthyopterygia indet. from Marmierfjellet (Spathian). (A) PMO 229.911. A1 - Anterior view, A2 - Posterior view, A3 - Lateral view. (B) PMO 229.912. B1 - Anterior view, B2 - Posterior view, B3 - Lateral view. (C) PMO 229.913. C1 Anterior view, C2 - Posterior view, C3 - Lateral view. (D) PMO 229.914. D1 - Anterior view, D2 - Posterior view, D3 - Lateral view. (E) PMO 229.915. E1 - Anterior view, E2 - Posterior view, E3 - Lateral view. Scale bar $=10 \mathrm{~mm}$, anterior is to the left for photographs in lateral view. Abbreviations: aP - apophysis, $n F-$ notochordal foramen. 


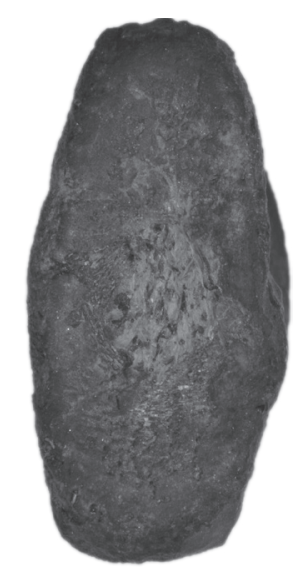

A1

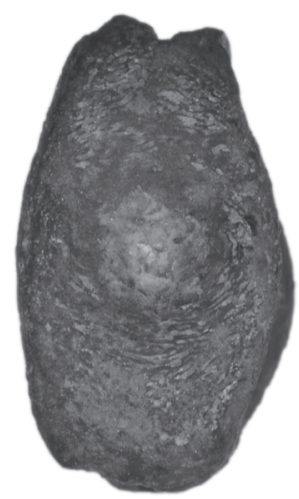

B1

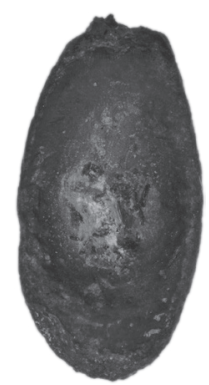

C1

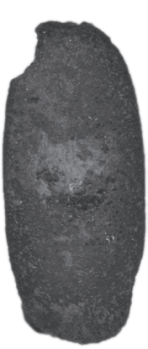

D1

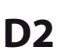

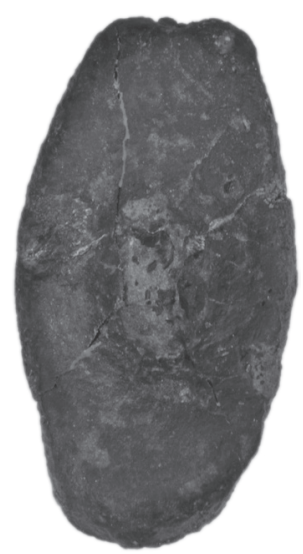

A2

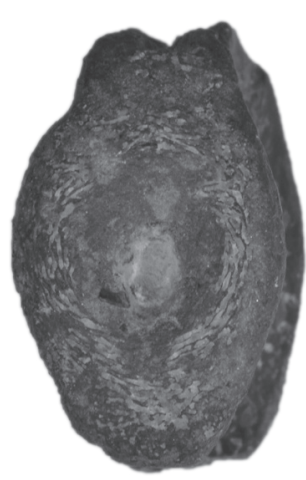

B2

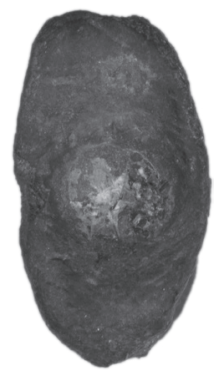

C2

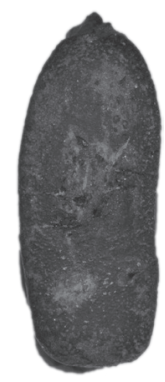

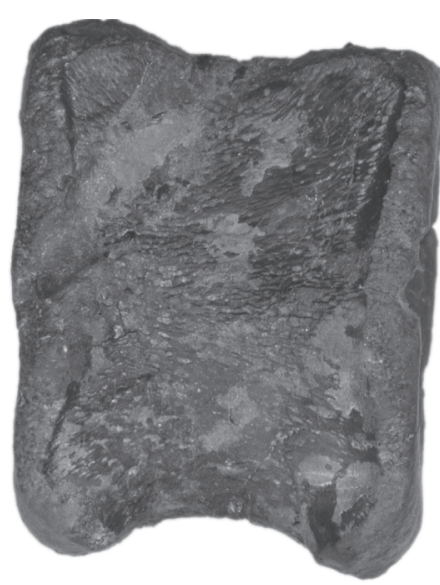

A3

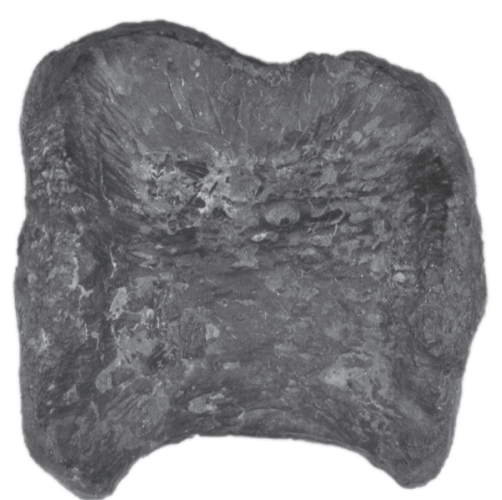

B3

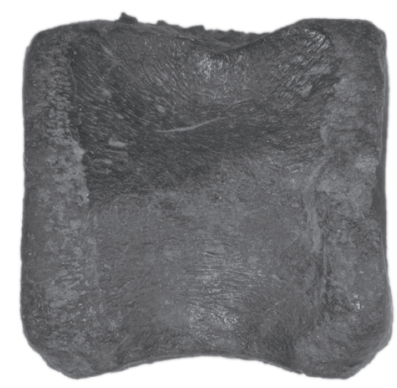

C3

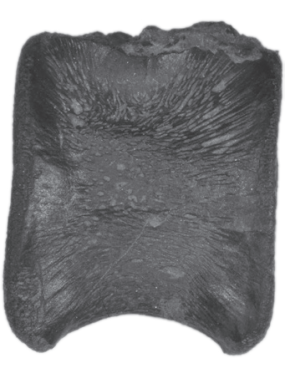

D3

Figure 13. Posterior caudal vertebrae of Ichthyopterygia indet. from Marmierfjellet (Spathian). (A) PMO 230.135. A1 - Anterior view, A2 - Posterior view, A3 - Lateral view. (B) PMO 230.136. B1 - Anterior view, B2 - Posterior view, B3 - Lateral view. (C), PMO 230.137. C1 Anterior view, C2 - Posterior view, C3 - Lateral view. (D) PMO 230.138. D1 - Anterior view, D2 - Posterior view, D3 - Lateral view. Scale bar $=10 \mathrm{~mm}$, anterior is to the left for photographs in lateral view. 


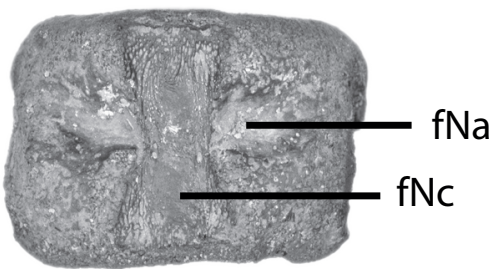

A1

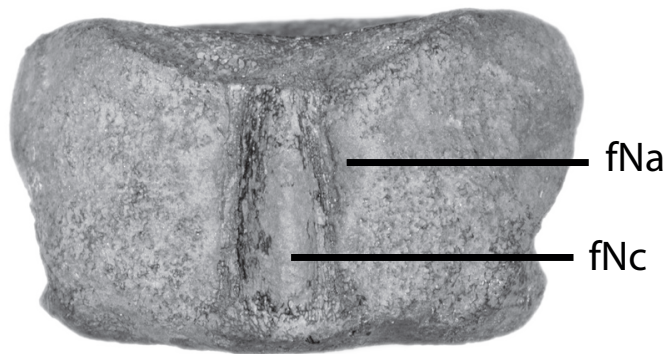

B1

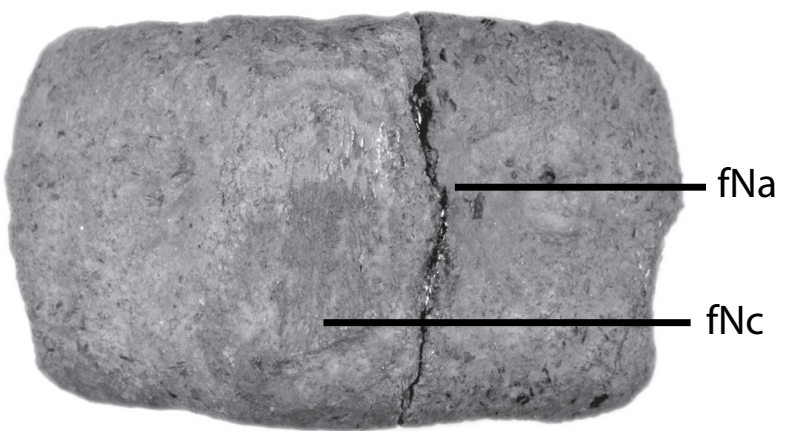

C1

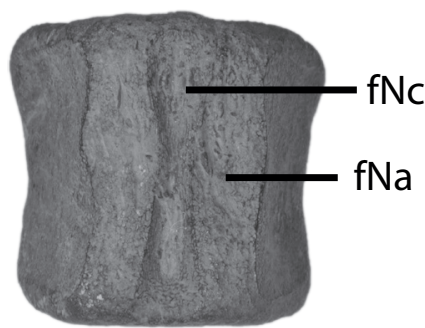

D1

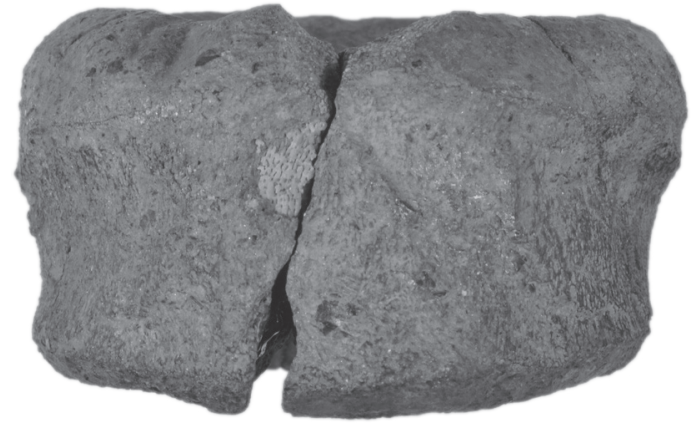

C2

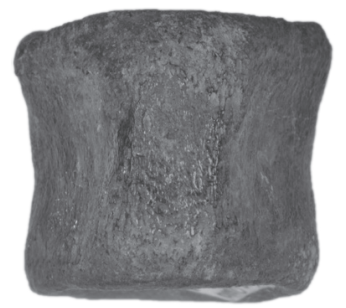

D2

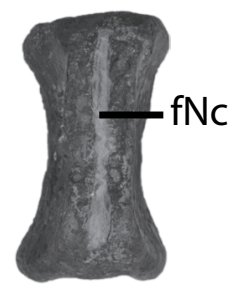

E1

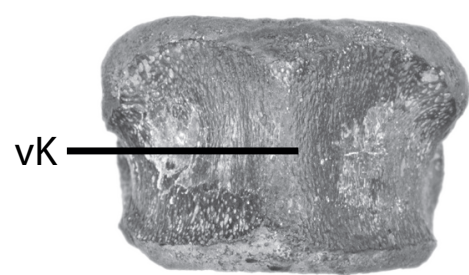

A2

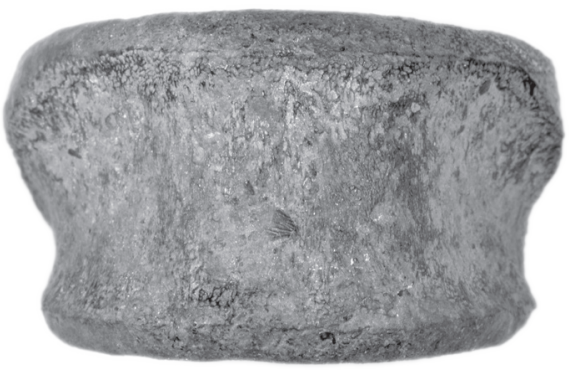

B2 
pers. obs. CPE), the assumed splenials are located ventral to the dentaries where they contribute to a large part of the symphysis (Sander \& Faber, 2003).

Ichthyopterygian affinities of the vertebrae are supported from the discoidal shape; the centra are dorsoventrally higher than anteroposteriorly long (Sander, 2000; Motani, 2005). This is observed in most ichthyopterygians including Early Triassic Gulosaurus (Cuthbertson et al., 2013), but differs from Grippia, Utatsusaurus and Chaohusaurus where the centra are longer than high (Wiman, 1928; Maisch \& Matzke, 2000). The more primitive ichthyopterygians are assumed to have an anguilliform swimming mode, while later taxa were thunniform (Motani et al., 1996). Motani et al. (1996) suggested that the deep fusiform body common in the more derived ichthyopterygians began evolving with the evolution of discoidal centra. A large area of contact between two centra, as was probably the case in the dorsal centra here and a short length of the centra will minimize intervertebral movement (Buchholtz, 2001).

If the caudal vertebrae are correctly identified, a neural spine articulation in the tail is present, a diagnostic character of Ichthyopterygia (Ji et al., 2016). Further assignment is not done in this contribution, as the features of the vertebrae might correspond to several genera. Grippia centra (Fig. 8) share the anterior outline of the cervical and dorsal vertebrae, but as they are cylindrical instead of discoidal, significantly smaller and possess a patch of periosteal bone anterior to the apophysis in lateral view (Fig. 8B), the vertebrae do not belong to this genus.

The vertebrae might belong to Omphalosaurus as they share some features with previously described Omphalosaurus (Sander \& Faber, 2003). The atlas from the Grippia bonebed has the same features as previously described atlases of Omphalosaurus and a convex anterior face and a deeply concave posterior face (Sander \& Faber, 2003). However, the similarities are also shared by other taxa, such as deeply amphicoelous and nearly notochordal vertebrae that are described for Gulosaurus (Brinkman et al., 1992). The periosteum of the vertebrae is "wrinkled", a feature not described for Omphalosaurus. Brinkman et al. (1992) described striations on the bone surface of Utatsusaurus, but unfortunately no picture was presented in the paper.

The general lack of compact bone in cranial and postcranial elements has been noted as an important feature for referral to Omphalosaurus, of which several specimens display cancellous bone of primary origin and cyclic growth (Sander \& Faber, 2003; Wintrich et al., 2017). However, very light skeletal elements is an adaptation found in many marine animals, and this feature alone is not phylogenetically viable as recent studies on many taxa of Triassic-Cretaceous ichthyopterygians show that there is no increase in compactness in any part of ichthyopterygian vertebral centra (Nakajima et al., 2014; Houssaye et al., 2018). A reduction of bone mass is assumed to improve locomotion, especially the ability to accelerate and manoeuvre, and has been linked to a rapidly growing animals with active metabolism, and possibly homeothermy (de Buffrénil \& Mazin, 1990; Nakajima et al., 2014). This is an advantage for more rapid swimmers and animals cruising for a longer time in open water (de Ricqlès \& de Buffrénil, 2001). Ichthyopterygians have vertebrae with very limited endochondral territory and a special type of primary bone deposits mimicking fibrolamellar bone, found in e.g., dinosaurs (Houssaye et al., 2018).

Omphalosaurus is commonly interpreted as a durophagous animal based on the massive jaw elements and the tooth microstructure (Mazin, 1986; Sander, 1999, 2000), and massive elements are observed in this study. The tooth enamel shows a smooth enamel-dentinejunction, together with a bulbous shape and uneven surface of the enamel, characteristic for durophagous ichthyopterygians (Figs. 9-11) (Sander, 1999). By comparing the size of the tooth-bearing bones and the size of the teeth, the teeth are generally larger and more irregular in size for the premaxillae than the dentaries. This was also observed by Sander \& Faber (2003) for the Omphalosaurus cf., O. nevadanus specimen MBG 1500. Animals with crushing dentition often have short snouts with the dentition placed far back to maximize the bite force, in contrast to Omphalosaurus (Sander \& Faber, 2003; Wintrich et al., 2017). In premaxilla PMO 229.922 the teeth are placed on the anterior half of the occlusion surface, while in the dentaries the teeth are mainly concentrated along the symphysis, (e.g., PMO 229.919). The teeth are also more widespread in the premaxillae.

If the ?premaxilla of PMO 229.922 is mirrored to get an impression of the upper jaw, the result is a wide occlusion surface, similar to that of the dentaries. Motani et al. (2015) found durophagy unlikely for Omphalosaurus due to the teeth arrangement and the assumable weak forces in the front of the jaws, and suggested that it grasped food with an extended jaw symphysis. A spatula shaped snout was described for the largely incomplete holotype of O. nettarhynchus (MGL45452; Mazin \& Bucher, 1987). The medial surface of the premaxilla has been suggested to be an active grinding surface (Sander \& Faber, 1998), but according to Sander \& Faber (2003) it is more likely that the medial sides of the two premaxillae met in the sagittal plane of the upper jaw in a symphysis. In the ?premaxilla PMO 229.922 it seems that at least a part of the medial surface was an active grinding surface, due to the polished cross section of the tooth crowns in lateral view. The only finished surfaces of the tooth-bearing bones are the occlusion surface and parts of the medial surface. The lack of periosteal bone could imply that these surfaces were covered by other bones or that they are worn. A loose jaw symphysis will able the dentaries to 
be mobile independent of each other and could explain the wear of the teeth on the medial surface, caused by the dentaries grinding in the symphysis. The lateral surface of the premaxilla (Fig. 3B4) resembles that of a maxilla from a Shastasaurus specimen, and similar structures have been observed in derived ichthyosaurs and might relate to dermal sensory structures or possibly lip musculature (Kear, 2005).

\section{Conclusions}

In this study, fossil vertebrate remains from the Grippia and Lower Saurians niveaus at Spitsbergen are described. Robust jaw elements are interpreted as ?premaxillae and dentaries from the enigmatic animal Omphalosaurus, while several hundred vertebrae display a resembling morphology to each other, and are referred to Ichthyopterygia. The vertebrae differ from those of Grippa and of Cymbospondylus, but cannot at the moment be referred to genus or species level. Additional material from the same layers has been collected and might reveal more about the marine ecosystems at Spitsbergen in the first radiations after the Permian/ Triassic mass extinction.

Acknowledgments. A huge thank you is offered to the Spitsbergen Mesozoic Research Group, with a large thank you to the volunteers $\varnothing$. Enger, S. Larsen, T. Wensås, M. Høyberget, C.S. Bjorå and L. Kristiansen. A special thank you to A. Reisdorf and H.-A. Nakrem. Great thanks to M. Sander and T. Wintrich at the Steinmann Institute of Geology, Mineralogy and Paleontology, University of Bonn, for discussions and specimen access. Thanks to M.-L K. Funke, B. Lund and J. Bratvold for preparation. The following permits were given by the Governor of Svalbard for the excavations in 2014 and 2015, RiS 6725, 2013/1222-2 and RiS 10227, 2015/00326-2. Sponsors for the excavations were Spitsbergen Travel, National Geographic (grants GEFNE158-15; GEFNE 10814), Bayern gas Norge, Tullow Oil and CGG. The reviewers Benjamin Kear and Dean Lomax are warmly thanked for comments that helped improve the manuscript considerably.

\section{References}

Arkhangelsky, M.S., Zverkov, N.G., Zakharov, Y.D. \& Borisov, I.V. 2016: On the first reliable find of the genus Tholodus (Reptilia: Ichthyopterygia) in the Asian peripheral area of the Panthalassic ocean. Paleontological Journal 50, 78-86. https://doi.org/10.1134/S0031030115060040.

Bratvold, J., Delsett, L.L. \& Hurum, J.H. 2018: Chondrichthyans from the Grippia bonebed (Early Triassic) of Marmierfjellet, Spitsbergen. Norwegian Journal of Geology 98, 189-217. https://dx.doi.org/10.17850/njg98-2-03

Brinkman, D.B.,Zhao, X.J. \& Nicholls, E.L. 1992: A primitive ichthyosaur from the Lower Triassic of British Columbia, Canada. Palaeontology $35,465-474$.
Buchholtz, E.A. 2001: Swimming styles in Jurassic ichthyosaurs. Journal of Vertebrate Paleontology 21, 61-73. https://doi.org/10.1671/0272-4634(2001)021[0061:SSIJI]2.0.CO;2.

Cox, C.B. \& Smith, D.G. 1973: Review of Triassic vertebrate faunas of Svalbard. Geological Magazine 110, 405-418. https://doi.org/10.1017/S0016756800036190.

Cuthbertson, R.S., Russell, A.P. \& Anderson, J.S. 2013: Cranial morphology and relationships of a new grippidian (Ichthyopterygia) from the Vega-Phroso Siltstone Member (Lower Triassic) of British Columbia, Canada. Journal of Vertebrate Paleontology 33, 831-847. https://doi.org/10.1080/02724634.2013.755989.

Dallmann, W.K. 2015: Geoscience Atlas of Svalbard. Norwegian Polar Institute, $292 \mathrm{pp}$.

de Buffrénil, V. \& Mazin, J.-M. 1990: Bone histology of the ichthyosaurs: comparative data and functional interpretation. Paleobiology 16, 435-447. https://doi.org/10.1017/S0094837300010174.

de Ricqlès, A. \& de Buffrénil, V. 2001: Bone histology, heterochronies and the return of tetrapods to life in water: were are we? In Mazin, J.-M. \& de Buffrénil, V. (eds.): Secondary Adaptation of Tetrapods to Life in Water, Verlag Dr. Friedrich Pfeil, pp. 289-310.

Engelschiøn, V.S., Delsett, L.L., Roberts, A.J. \& Hurum, J.H. 2018: Largesized ichthyosaurs from the Lower Saurian niveau of the Vikinghøgda Formation (Early Triassic), Marmierfjellet, Spitsbergen. Norwegian Journal of Geology 98, 239-265.

https://dx.doi.org/10.17850/njg98-2-05.

Hansen, B.B., Hammer, O. \& Nakrem, H.A. 2018: Stratigraphy and age of the Grippia niveau bonebed, Lower Triassic Vikinghogda Formation, Spitsbergen. Norwegian Journal of Geology 98, 175-187. https://dx.doi.org/10.17850/njg98-2-02.

Houssaye, A., Nakajima, Y. \& Sander, P.M. 2018: Structural, functional, and physiological signals in ichthyosaur vertebral centrum microanatomy and histology. Geodiversitas 40, 161-170. https://doi.org/10.5252/geodiversitas2018v40a7.

Huene, F.V. 1956: Paläontologie und Phylogenie der Niederen Tetrapoden. Gustav Fischer Verlag, 716 pp.

Hurum, J.H., Engelschiøn, V.S., Økland, I., Bratvold, J., Ekeheien, C., Roberts, A.J., Delsett, L.L., Hansen, B.B., Mørk, A., Nakrem, H.A., Druckenmiller, P.S. \& Hammer, Ø. 2018: The history of exploration and stratigraphy of the early to middle Triassic vertebrate bearing strata of Svalbard (Sassendalen Group, Spitsbergen). Norwegian Journal of Geology 98, 165-174.

https://dx.doi.org/10.17850/njg98-2-04.

Ji, C., Jiang, D.-Y., Motani, R., Rieppel, O., Hao, W.-C. \& Sun, Z.-Y. 2016: Phylogeny of the Ichthyopterygia incorporating recent discoveries from South China. Journal of Vertebrate Paleontology 36. https://doi.org/10.1080/02724634.2015.1025956.

Jiang, D., Motani, R., Hao, W., Schmitz, L., Rieppel, O., Sun, Y. \& Sun, Z. 2008: New primitive ichthyosaurian (Reptilia, Diapsida) from the Middle Triassic of Panxian, Guizhou, southwestern China and its position in the Triassic biotic recovery. Progress in Natural Science 18, 1315-1319. https://doi.org/10.1016/j.pnsc.2008.01.039.

Kear, B.P. 2005: Cranial morphology of Platypterygius longmani Wade, 1990 (Reptilia: Ichthyosauria) from the Lower Cretaceous of Australia. Zoological Journal of the Linnean Society 145, 583-622. https://doi.org/10.1111/j.1096-3642.2005.00199.x.

Kuhn, O. 1934: Pars 63. Ichthyosauria. Fossilium Catalogus I: Animalia. Dr. W. Junk Publisher, 75 pp.

Maisch, M.W. 2010: Phylogeny, systematics, and origin of the Ichthyosauria - the state of the art. Palaeodiversity, 151-214.

Maisch, M.W. \& Matzke, A.T. 2000: The Ichthyosauria. Stuttgarter Beiträge zur Naturkunde Serie B, 1-159.

Maxwell, E.E. \& Kear, B.P. 2013: Triassic ichthyopterygian assemblages of the Svalbard archipelago: a reassessment of taxonomy and distribution. Geologiska Föreningen i Stockholm Förhandlingar 135, 85-94. https://doi.org/10.1080/11035897.2012.759145.

Mazin, J.M. 1983: Omphalosaurus nisseri (Wiman, 1910), un ichthyoptérygien à denture broyeuse du Trias moyen du Spitsberg. Bulletin du Muséum national d'histoire naturelle Paris C Serie IV 5, 
243-263.

Mazin, J.M. 1986: A new interpretation of the type specimen of Omphalosaurus nevadanus Merriam 1906. Palaeontographica Abteilung A 195, 19-27.

Mazin, J.M. \& Bucher, H. 1987: Omphalosaurus nettarhynchus, une nouvelle espèce d'Omphalosauridé (Reptilia, Ichthyopterygia) du Spathien de la Humboldt Range (Nevada, U.S.A.). Comptes Rendus de l'Academie des Sciences 305, 823-828.

Mazin, J.M., Suteethorn, V., Buffetaut, E., Jaeger, J.J. \& Helmckeingavat, R. 1991: Preliminary description of Thaisaurus chonglakmanii n. g., n. sp., a new ichthyopterygian (Reptilia) from the Early Triassic of Thailand. Comptes Rendus De L Academie Des Sciences Serie II 313, 1207-1212.

Merriam, J.C. 1906: Preliminary note on a new marine reptile from the Middle Triassic of Nevada. Bulletin of the department of geology of the University of California 5, 75-79.

Merriam, J.C. 1908: Triassic Ichthyosauria, with special reference to the American forms. Memoirs of the University of California 1, 1-193.

Merriam, J.C. \& Bryant, H.C. 1911: Notes on the dentition of Omphalosaurus. Bulletin of the department of geology of the University of California 6, 329-332.

Motani, R. 1999: Phylogeny of the Ichthyopterygia. Journal of Vertebrate Paleontology 19, 473-496. https://doi.org/10.1080/02724634.1999.10011160.

Motani, R. 2000: Is Omphalosaurus ichthyopterygian? - A phylogenetic perspective. Journal of Vertebrate Paleontology 20, 295-301. https://doi.org/10.1671/0272-4634(2000)020[0295:IOIAPP]2.0.CO;2.

Motani, R. 2005: Evolution of fish-shaped reptiles (Reptilia: Ichthyopterygia) in their physical environments and constraints. Annual Review of Earth and Planetary Sciences 33, 395-420. https://doi.org/10.1146/annurev.earth.33.092203.122707.

Motani, R., You, H. \& McGowan, C. 1996: Eel-like swimming in the earliest ichthyosaurs. Nature 382, 347-348. https://doi.org/10.1038/382347a0.

Motani, R., Chen, X.-H., Jiang, D.-Y., Cheng, L., Tintori, A. \& Rieppel, O. 2015: Lunge feeding in early marine reptiles and fast evolution of marine tetrapod feeding guilds. Scientific Reports 5, 1-8. https://doi.org/10.1038/srep08900.

Mørk, A., Elvebakk, G., Forsberg, A.W., Hounslow, M.W., Nakrem, H.A., Vigran, J.O. \& Weitschat, W. 1999: The type section of the Vikinghøgda Formation: a new Lower Triassic unit in central and eastern Svalbard. Polar Research 18, 51-82. https://doi.org/10.3402/polar.v18i1.6558.

Nakajima, Y., Houssaye, A. \& Endo, H. 2014: Osteohistology of the Early Triassic ichthyopterygian reptile Utatsusaurus hataii: Implications for early ichthyosaur biology. Acta Palaeontologica Polonica 59, 343352.

Owen, R. 1840: Report on British fossil reptiles. Part I. Report of the British Association for the Advancement of Science 9, 43-126.

Sander, P.M. 1992: Cymbospondylus (Shastasauridae: Ichthyosauria) from the Middle Triassic of Spitsbergen: Filling a Palaeobiogeographic gap. Journal of Paleontology 66, 332-337. https://doi.org/10.1017/S0022336000033825.

Sander, P.M. 1999: The microstructure of reptilian tooth enamel: terminology, function, and phylogeny. Münchner geowissenschaftliche Abhandlungen, 1-102.

Sander, P.M. 2000: Ichthyosauria: their diversity, distribution, and phylogeny. Paläontologische Zeitschrift 74, 1-35.

https://doi.org/10.1007/BF02987949.

Sander, P.M. \& Faber, C. 1998: New finds of Omphalosaurus and a review of Triassic ichthyosaur paleobiogeography. Paläontologische Zeitschrift 72, 149-162. https://doi.org/10.1007/BF02987823.

Sander, P.M. \& Faber, C. 2003: The Triassic marine reptile Omphalosaurus: Osteology, jaw anatomy, and evidence for ichthyosaurian affinities. Journal of Vertebrate Paleontology 23, 799816. https://doi.org/10.1671/6.

Shikama, T., Kamei, T. \& Murata, M. 1978: Early Triassic Ichthyosaurus, Utatsasaurus shataii Gen. et Sp. Nov., from the Kitakami Massif,
Northeast Japan. Tohoku Univeristy Scientific Reports 48, 77-97.

Tichy, G. 1995: Ein früher, durophager Ichthyosaurier (Omphalosauridae) aus der Mitteltrias der Alpen. Geologischpaläontologische Mitteilungen Innsbruck 20,349-369.

Wiman, C. 1910: Ichthyosaurier aus der Trias Spitzbergens. Bulletin of the Geological Insitution of the University of Uppsala 10, 124-148.

Wiman, C. 1916: Notes on the marine Triassic reptiles fauna of Spitzbergen. University of California publications, Bulletin of the department of geology 10, 63-73.

Wiman, C. 1928: Eine neue marine Reptilien-Ordnung aus der Trias Spitzbergens. Bulletin of the Geological Insitution of the University of Uppsala 22, 183-196.

Wiman, C. 1933: Über Grippia longirostris. Nova Acta Regiae Societatis Scientiarum Upsaliensis 9, 1-20.

Wintrich, T., Hagdorn, H. \& Sander, P.M. 2017: An enigmatic marine reptile-the actual first record of Omphalosaurus in the Muschelkalk of the Germanic basin. Journal of Vertebrate Paleontology 37. https://doi.org/10.1080/02724634.2017.1384739.

Zhou, M., Jiang, D.-Y., Motani, R., Tintori, A., Ji, C., Sun, Z.-Y., Ni, P.-G. \& Lu, H. 2017: The cranial osteology revealed by three-dimensionally preserved skulls of the Early Triassic ichthyosauriform Chaohusaurus chaoxianensis (Reptilia: Ichthyosauromorpha) from Anhui, China. Journal of Vertebrate Paleontology 37. https://doi.org/10.1080/02724634.2017.1343831. 
